\title{
Fonctions des inscriptions au moyen âge
}

\section{Robert Favreau}

\section{Citer ce document / Cite this document :}

Favreau Robert. Fonctions des inscriptions au moyen âge. In: Cahiers de civilisation médiévale, 32e année ( $\left.n^{\circ} 127\right)$, Juilletseptembre 1989. pp. 203-232;

doi : https://doi.org/10.3406/ccmed.1989.2440

https://www.persee.fr/doc/ccmed_0007-9731_1989_num_32_127_2440

Fichier pdf généré le 25/03/2019 


\section{Resumen}

Estudiar las funciones de las inscripciones conduce a entender mejor su papel y abrazar mejor lo que puede ser su aportación a la historia. Los epitafîos, la categoria mas importante, pretenden conservar la memoria del difunto, pedir para él oraciones, recordar lo vano del mundo. De esta manera, nos traen informaciones sobre la vida del difunto, la fe, la actitud delante de la muerte. Numerosas inscripciones aseguran la "publicidad» de actas tanto pùblicas como privadas, conmemoran acontecimientos, entregan a la posteridad los nombres de los comanditarios de la obra o de sus autores. Otras tienen todavia una función litùrgica : hacer memoria de la dedicatoria de una iglesia, de la consagración de un altar, de una translación de reliquias, del otorgamiento de indulgencias, de las fundaciones de misas o aniversarios. El papel de ciertos epigrafes consiste en explicar y comentar un programa iconográfico, y por eso se deben colocar en un contexto exegético y teológico. Por fin, ciertas inscripciones constituyen una verdadera predicación para los fieles.

\section{Résumé}

Étudier les fonctions des inscriptions, c'est mieux comprendre leur rôle et mieux cerner ce que peut être leur apport à l'histoire. Les épitaphes, catégorie la plus importante, ont pour fonctions de garder la mémoire du défunt, demander pour lui des prières, rappeler la vanité de ce monde. Par là elles nous apportent des renseignements sur les vies, la foi, l'attitude devant la mort. De nombreuses inscriptions ont pour fonction d'assurer la publicité d'actes publics ou privés, de commémorer des événements, de faire passer à la postérité les noms de ceux qui ont commandé l'œuvre ou l'ont réalisée. D'autres ont une fonction liturgique, rappeler la dédicace d'une église, la consécration d'un autel, une translation de reliques, l'octroi d'indulgences, des fondations de messes ou d'anniversaires. Certaines ont pour rôle d'expliquer, de commenter un programme inocographique et doivent être replacées dans un contexte exégétique et théologique. Enfin certaines inscriptions constituent une véritable prédication à l'intention des fidèles. 


\title{
*Robert FAVREAU
}

\section{Fonctions des inscriptions au moyen âge}

\begin{abstract}
Réstiví
Étudier les fonctions des inscriptions, c'est mieux comprendre leur ròle et mieux cerner ce que peut ètre leur apport à l'histoire. Les épitaphes, catégorie la plus importante, ont pour fonctions de garder la mémoire du défunt, demander pour lui des prières, rappeler la vanité de ce monde. Par là elles nous apportent des renseignements sur les vies, la foi, l'attitude devant la mort. De nombreuses inseriptions ont pour fonction d'assurer la publicité d'actes publics ou privés, de commémorer des événements, de faire passer à la postérité les noms de ceux qui ont commandé l'œuvre ou l'ont réalisée. D'autres ont une fonction liturgique, rappeler la dédicace d'une église, la consécration d'un autel, une translation de reliques. l'octroi d'indulgences, des fondations de messes ou d'anniversaires. Certaines ont pour ròle d'expliquer, de commenter un programme inocographique et doivent être replacées dans un contexte exégétique et théologique. Enfin certaines inscriptions constituent une véritable prédication à l'intention des fidèles.

Estudiar las funciones de las inscripciones conduce a entender mejor su papel y abrazar mejor lo que puede ser su aportación a la historia. los epitafios, la categoria más importante, pretenden conservar la memoria del difunto, pedir para él oraciones, recordar lo vano del mundo. De esta manera, nos traen informaciones sobre la vida del difunto, la fe, la actitud delante de la muerte. Numerosas inscripciones aseguran la "publicidad» de actas tanto públicas como privadas, conmemoran acontecimientos. entregan a la posteridad los nombres de los comanditarios de la obra o de sus autores. Otras tienen todavia una función litúrgica : hacer memoria de la dedicatoria de una iglesia, de la consagración de un altar, de una translación de reliquias, del otorgamiento de indulgencias, de las fundaciones de misas o aniversarios. El papel de ciertos epígrafes consiste en explicar y comentar un programa iconográfico, y por eso se deben colocar en un contexto exegético y teológico. Por fin, ciertas inscripciones constituyen una verdadera predicación para los fieles.
\end{abstract}

L'épigraphie constitue une source historique parmi d'autres. L'historien peut done l'interroger sous de multiples aspects : renseignements biographiques, mentions d'événements historiques, noms d'auteurs, témoignage de la culture d'une époque, reflet d'une foi, évolution de la langue, etc. C'est une source d'un type particulier, dans la mesure où l'inscription accompagne souvent une iconographie et l'historien y cherchera alors un complément à l'œuvre, de la simple identification de scènes ou de personnages au commentaire théologique le plus èlevé. Elle a deux caractères propres, car elle vise "une publicité universelle et durable" ${ }^{1}$. La durée, c'est ce qui préoccupe tous les auteurs de chroniques ou histoires. "Voici l'exposé de l'enquête entreprise par Hérodote d'Halicarnasse pour empêcher que les actions accomplies par les hommes ne s'effacent avec le temps", écrivait, l'historien grec du $v^{*}$ s. avant notre ère. La publicité la plus générale est un trait caractéristique de l'inscription, et elle justifie que très fréquemment le texte épigraphique comporte une apostrophe au lecteur.

1. Robert Favneal, "Lépigraphie médievale", Cahiers ciril. médiét.. XII, 1969. p. 395. 
VE RES PRETERITAS VALEAT DA.MP.VARE

ISTE REI (EESTE DAT SICVA LAPIS MA.VIFESTE,

Afin que l'àge ne vienne pas condamner le passé à l'oubli.

Cette pierre enseigne les faits de façon manifeste.

dit une inscription du linteau de la porte de l'église de Nantua (Ain) ${ }^{2}$, résumant bien ces deux caractéristiques de durée et de publicité. Une façon de rendre comple de ce que représente l'épigraphie comme source pour l'historien, c'est aussi de se demander pourquoi on a fait figurer sur pierre ou autre matière des informations particulières, quelles sont les différentes fonctions de l'épigraphie, en interrogeant sur ce point, le plus possible, les inscriptions elles-mèmes.

Les épitaphes constituent l'ensemble de loin le plus important des inscriptions. Si l'on se demande pourquoi de tout temps, les hommes ont tenu à laisser un message au-dela de leur mort, on peut distinguer dans les épitaphes, une triple fonction : garder la mémoire du défunt, demander pour lui des prières, rappeler aux proches, mais aussi à tous ceux qui à l'avenir liront l'epitaphe. la vanité de ce monde, et donc les exhorter à mener une vie droite.

"Absalom avait entrepris de se faire ériger, de son vivant, la stele qui se trouve dans la vallee du Roi, car il s'était dit : 'Je n’ai pas de fils pour perpéluer mon nom'. Il donna donc son nom a la stèle ${ }^{3}$. Ce souci de perpétuer la mémoire est général. C'est pour la bergère Daphnis que Virgile. dans les Bucoliques, fait composer une épitaphe en vers. Dans une lettre écrite en 107 Pline le Jeune sindigne de ce que les restes de Verginius Rufus, un important personnage de ce temps, aient éte laissés à l’abandon, sans épitaphe - sine nomine jacere - alors qu'il avait préparé les deux vers qui devaient être placés sur son tombeau ${ }^{5}$. A la mort de leur fils de trois ans et demi Flavius Gentianus et Palesta, de Vienne, font placer sur sa tombe une épitaphe "en témoignage de leur amour" ${ }^{6}$. Bède nous rapporte que, lorsque le roi Caedwalla mourut a Rome en 689, le pape Serge I"r ordonna d’inscrire une épitaphe sur sa tombe, afin de garder, "pour les siècles à venir", le souvenir de la piété du roi?. C’est aussi la prière que formule saint Théodore, évèque de Pavie, de 770 a 785 , a la fin de son epitaphe : Mei memores, per secula, fralres. A Hulne (Northumberland) au xur s., le prêtre Thomas, un homme bon et pieux, s'est fait préparer un tombeau de pierre. gravé à son nom : il en fera le don aux frères du Nont-Carmel pour enterrer l'archidiacre Thomas de Hertiord ${ }^{9}$.

Mème si beaucoup de tombes sont anonymes, un grand nombre comportent le nom du défunt et

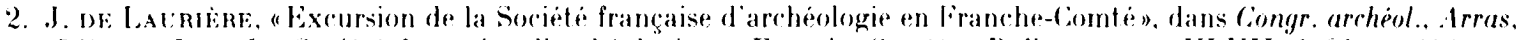
1880. p. 539; - ID.. "La Sociéte franģase d archéologie en Franche-Comte". Bull. monum.. XI.VII. 1881. p. 31.4.

3. Il samuel, Xlill, 18. Voir Genese. XXXV. 20, pour le tombeau que Jacob fait elever pour Rachel.

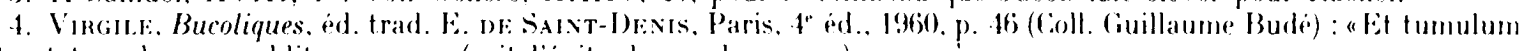
facite ef tumulo superaddite carmen" (suit l'epitaphe en deux vers).

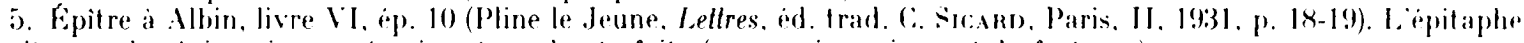
devrait rappeler a jamais sa memoire el ses hauts faits ("memoria .... immortale factum»).

6. Recueil des inscriptions chrétiennes de la Gaule antérieures à la renaissance carolingienne. XV. Yiennoise du . Vord. èd. Francoise I)rscombes, Paris, 196"), n" 1.18. p. 19.1.

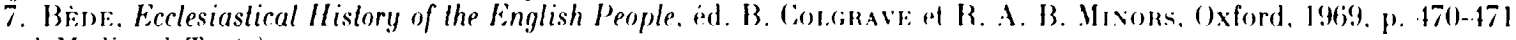
(()xford Medieval Texts).

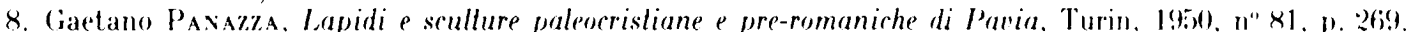

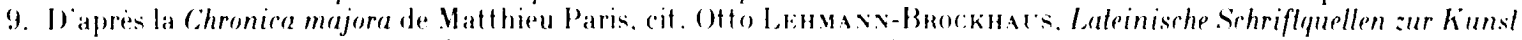

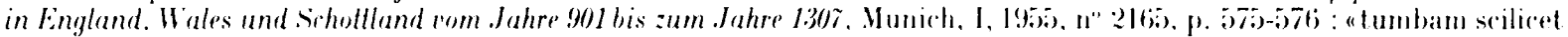
lapideam, nomine meo videlicet intitulatam, ubi hoc nomen Thomas insculpitur. in qua ego Thomas peccator proposui intumulari". 
son éloge ${ }^{10}$. Une inscription chrétienne de Vienne nous dit qu'il s'agit d'un usage ${ }^{11}$, et le chroniqueur anglais qui rapporte l'invention, en 1257, du tombeau de saint Alban, précise que le tombeau contenait une lampe de plomb sur laquelle, "selon la coutume des anciens", était écrit le nom d'Alban ${ }^{12}$. La formulation la plus simple d'une épitaphe consiste donc en la simple mention du nom du défunt. C'est le cas, fréquemment, pour les premières inscriptions chrétiennes. Ainsi. au cimetière mérovingien de Yeuvicq- Montguyon, trente-neuf sarcophages comportent une inscription, qui se limite, dans tous les cas, à un nom ${ }^{13}$. Le plus souvent cependant, comme nous le dit Isidore de Séville, l'épitaphe comporte "la vie, les mours, l'àge" du défunt ${ }^{14}$, ce que reprend un chroniqueur à propos de la mort de la fille du roi d'Écosse en 1115: sur le tombeau de la princesse, on écrivit en lettres d'or, brièvement, sa vie et son origine rovale - vitam et originem, breviter ${ }^{15}$

Les épitaphes s'annoncent souvent elles-mèmes au lecteur comme destinées à leur enseigner le nom de celui qui repose dans le tombeau:

NOMEN SI QLAERIS ..., NOME.Y ... SI QLAERIS, HIC EST ..., aux cimetières de Callixte et de Santa Cristina à Rome ${ }^{16}$;

IJSCE QLI VELLIS NOSSE, QLII TEGIT TLMLLLM ISTE,

pour Cunincperga au virl"s. à Pavie ${ }^{17}$;

NOSCERE QIISOLE VELIT TE MLLO HOC OLIS CONIITUS EXSTET

PERLEGAT HLVC TITILLM, OMNIA SICQLE SCIET,

pour l'épitaphe de Walachfred abbe de Reichenau, par Raban Maur au IX" s. $^{18}$;

SI QLIS SCIRE CLPIT, HOC CLUS MEMBRA SEPILCRO

CLALDANTLR, CLARO COLLIGAT HOC TITLLO,

epitaphe de Mathilde de saxe au $x^{\prime \prime}$ s. $^{19}$;

HENC SPECTANS TLMLLLM TITLLO COGNOSCE SEPULTEM,

épitaphe d'Ilerluin, abbé du Bec-Hellouin mort en $1078^{20}$;

QII LEGIS HLVC TITLLEM SLBTLS COGNOSCE SEPLLTLM,

epitaphe de Guillaume le Conquérant par Baudri de Bourgueil ${ }^{21}$;

ASPICE, LECTOR, OPIS SCRIPTURAE MARMORIS HIJUS

OSTENISET TITLLES QIEM TEGIT HIC TEMULES,

epitaphe du fils du comte Alphonse à la Daurade de Toulouse au $\mathrm{xI}^{\prime \prime} \mathrm{s} .{ }^{22}$ :

10. Pridexce, Peristephanon, hymn. 11, v. 7-x (P.L.. L.X, c. 5333):

"Plurima litterulis signata sepulcra loquuntur

Hartyris aut nomen aut epigramma aliquod".

11. Recueil des inscriptions chréliennes de la Gaule ... XV. op. cit.. n"72. p. 324: "Titulum, ex more. dicabit".

12. (). Lengavis-Brockrats, op. cit., II. Munich, 1956. n"3952, p. 457: "In qua, secundum antiquorum consuetudinem. scriptus est hic titulus".

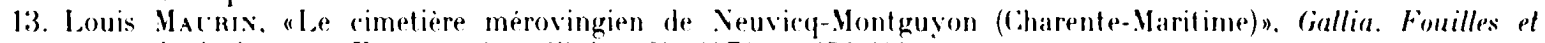
monuments archéologiques en France métropolitaine. 29, 1971, p. 151-189.

14. Elymologiae. I. I, XXXIX, P.L.. IXXXXII, e. 120) : "epitaphium ... est titulus mortuorum ... s.cribuntur enim ibi vita. mores et aetas eorum".

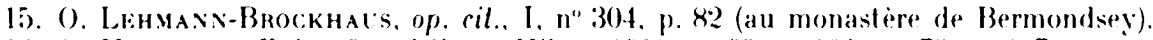

16. (). Martech, Epigrafia cristiana, Milan. 1910, n" 63, p. 102: n" 73, p. 107.

17. (i. Pa.vaz7.A, op. rit. n" 75, p. 2633-26.4.

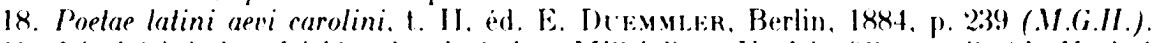

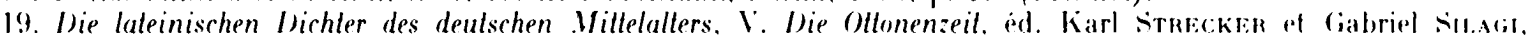

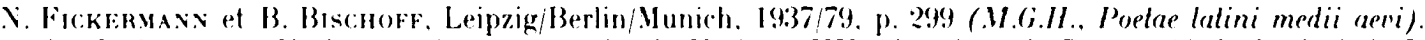

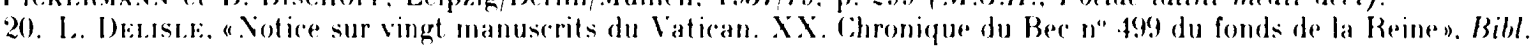

Ec. des Chartes, 8" s.. II, 1876, p. 521-527.

21. Les ceucres poetiques de Baudri de Bourgueil (1046-1130), ed. Ph. Abranams, Paris, 1926, p. 76.

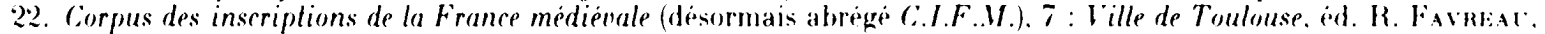

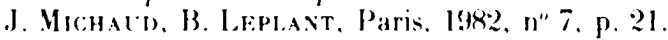


HIC JACENT VEVERABILES ABBATES QLORI W VOMINA LITTERIS IN LAPIDE IMSCLLPTIS IESIGNANTTR, ET ACTA IN TABLLARIO COPIOSLS DESCRIBLVTUR, inscription au cloitre de Clairvaux au XII" s. ${ }^{23}$;

HAEC QT' I METRA LEGIT, COG.VOSCET QLIS FIIT ISTE,

epitaphe du moine Gobert d'Apremont, a Villiers en Brabant en $1263^{24}$, etc.

Un certain nombre d'épitaphes répondent principalement à cette fonction de donner le nom du défunt, son origine, ses titres, sa vie. C'est le cas de la plupart des épitaphes du cloître de Roda, présentées à la façon d'un obituaire, par exemple:

\section{IIII IIUES FEBRE ARII OBIIT DOMINICLS, PRIOR CLAUSTRI, CANONICLS ET SACERDOS A.V.VO $M^{\circ} C C^{\circ} X X X^{0} V I I I I^{205}$,}

et de bon nombre des épitaphes du cloître de Silos du type : Obiit magister Ferninus monachus ${ }^{26}$. De façon générale les épitaphes des $\mathrm{X}^{\prime \prime}$-XIr s. dressent un portrait moral, toujours élogieux, souvent conventionnel, alors que celles de la fin du moyen âge s'étendent sur les titres et les carrières du défunt. Ainsi de l'inscription tumulaire d'Oudart d'Étables à Notre-Dame de Bon Repos à Marcilly : "Cy gist monseigneur Houdart d'Estables, chevalier, mestre d'ostel du roy nostre sire, jadis mestre de l'escurie, qui trespassa l'an mil et trois cenz "27, ou de celle de Marie de Bourgogne à Notre-Dame de Bruges, en 1482, où vingt-trois lignes sont consacrées aux titres et à la biographie de la princesse, une demande de prière occupant seulement la fin de la dernière ligne.

Mais les épitaphes chrétiennes n'ont généralement pas pour seule fonction de faire mémoire du défunt, et par là mème de lui assurer une certaine survie, d'empècher que son souvenir se perde à jamais. Parce que chrétiennes elles ont aussi pour objet une demande de prière pour le défunt, et souvent une dernière exhortation à s'attacher aux valeurs chrétiennes.

Dans ces deux fonctions l'adresse au lecteur est une partie quasi obligée. Le passant est invité à s'arrêter pour lire l'épitaphe. L'invitation peut être formulée par l'expression même d'Ovide, siste gradum, "arrête ton pas", que l'on trouve à Capoue, Rome, Trèves, Wissembourg, Brive, Le BecHellouin, ou par une expression voisine, fige gradum, subsiste viator, propende viator, carpe viator iter, larda viator iter, etc. Il s'agit bien de s'arrèter pour méditer le texte offert:

TU OLI PERGIS, SISTE ET PERLEGE,

Toi qui passes, arrète-toi et lis

dit le début de l'épitaphe de l'évèque I)ynamius à Avignon ${ }^{28}$,

QUI PROPERLS TRANSIS HLJUS MONLMENTA SEPLLCRI

IT RELIGAS TITULUM COMPRIME, QLAESO, GRADUM,

Passant, toi qui te hâtes, modère, je te prie, ton pas, afin de pouvoir lire l'inscription de ce tombeau,

invite le début de l'épitaphe d'Odon, abbé de Saint-Jean-d'Angély, mort en $1091^{29}$. Le passant est

23. Gallia christiana, IV. c. 8(0).

24. IIistoria monasterii Villariensis in Brabantia ordinis cisterciensis, dans E. Martènf et L. Durand, Thesauras novus anecdotorum. III, Paris, 1717. c. 1332.

25. Antonio I) eráx Gumol. "Las inscripciones medievales de la provincia de Huesca". dans Esludios de edad media de la corona de Aragón. vol. VIII. 1967, n" 109, p. 71.

26. Dom Marius Fínotix. Mistoire de l'abbaye de Silos. Paris. 1897, p. 306.

27 . Bibl. nat.. nouv. acc. lat. 2057 . p. 297.

28. C.I.F.M. 13: Gard, Lozere. Vaucluse, éd. R. Favreal, J. Michaud, B. Mora. Paris, 1988. p. 121.

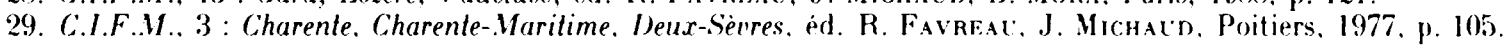


désigné par le mot viator, ou par des expressions telles que quisque ades, qui properas, qui transis, qui transitis, cette dernière peut-ètre inspirée des Lamentations de Jérémie (I, 12), O vos omnes qui transitis per viam, que l'on retrouve textuellement dans l'épitaphe d'une famille seigneuriale à Couffy au XIII" s. ${ }^{30}$.

L'épitaphe est écrite pour ètre lue. C'est par dizaines que se présentent les exemples d'invitation à la lecture : lector, qui legis ou legit, quicumque legis, expression déjà présente dans les épitaphes antiques ${ }^{31}$, quisque legis, quisque cernis, qui conspicis, quicumque recenses, respice, aspice, qui legerit istas litteras, omnes qui viderunt has litleras, ho vos fratres el sorores qui scitis litteras, etc. Le texte peut aussi s'adresser à ceux auxquels il sera lu à haute voix, selon les indications rares, mais précieuses, d'inscriptions anciennes des îles Britanniques, legentes quoque vel audientes, quicumque recitaverit manescriplum lapidem, quicumque explicaverit ${ }^{32}$. Il $y$ a souvent insistance pour que le texte soit lu rogo, precor, quaeso, oblestor vos omnes qui haec lecturi estis, à Oviedo en $8500^{33}$, Obsecro le frater titulum qui conspicis istum à Saint-Maximin de Trèves en 945$)^{34}$. C'est que le défunt compte sur des prières pour que I Dieu lui pardonne ses fautes et lui accorde la vie éternelle. Cette demande de prières, sans doute au moins sous-entendue dans toute épitaphe, est le plus souvent explicitée.

L épitaphe peut demander des prières de façon générale, et c'est souvent le cas pour les

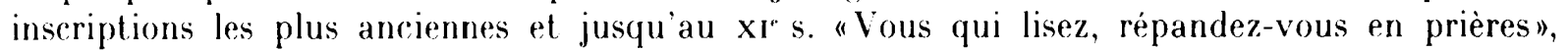
demande simplement l'abbé Aton à Angers en $835^{35}$, ou, également à Angers au IX" s., "Vous qui lisez, priez I)ieu" ${ }^{36}$. "O) lecteur, toi qui lis, prie», dit une épitaphe a Poitiers en $874^{37}$, "Vous qui lisez, priez pour moi", propose une épitaphe de S. Leo in Romagna de $882^{38}$, "Pour lui daignez adresser à Dieu de dignes prières", trouve-t-on à Milan en $900^{39}$. La formule lapidaire de 882, Ora ou Orate pro eon, est des plus fréquentes. Au XII" et surtout à partir du XIII" s. l'épitaphe demande la récitation du Notre-Père ou de quelques oraisons pour les défunts prises dans la liturgie des funérailles.

\section{QI'I PRESENTES LITTERAS LEGIS ET CONSIDERAS, IN DEFUNCTI .OMINE IIC "ABSOLVE, DOMINE" VEL "IDELS CLI PROPRILM" SIVE S.ALTEM "FIDELILW",}

demande l'évèque de Périgueux Jean d'Asside, en $1169^{40}$,

\section{OI I PRAESENTES LITTERAS LEGERIT, ORATIONEM DOMINICAM TER DEVOTE DICAT PRO ANIMA ILLITS,}

requiert l'archevèque de Narbonne, (iuillaume de Broue, en $1257^{41}$. Il faudrait aller plus loin, car

30. C.I.F.U., 1: Limousin. id. It.. Poitiers, 1978, p. 12.

31. "Prapteriens quicumque legis consiste, viator". epitaphe de Jucundus a Mayence (Carmina latina epigraphica. ed.

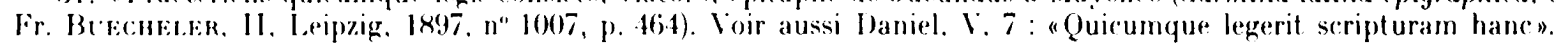

32. John Hociart. "Words and Crosses : The Inscribed stone Cross in Early Vedieval Britain and Ireland", dans

English . Medienal Sculpture in Britain and Ireland. B.1.R.. 152. 1986, p. 125-126.

33. Ciriaco Miguel Visit. Asturias monumental, epigrafica y diplomática .... Oviedo. 1887. p. 9.

34. Die christlichen Inschriften der Rheinlande. II. Die christlichen Inschriften von der . Ville des achlen bis zur Mille des dreizehnten Jahrhunderts. ed. F. X. KRal's. Fribourg-en-Brisgau/Leipzig. 1894. n"389. p. 190.

35). X. Barbier DF . Vontacit. Epigraphie du departement de Vaine-et-Loire. Angers, 1869, appendice, p. 443-444. "Pro quo qui legis. fundite. poseco, preces" (Angers, Musee).

36. "Qui legitis. Deum orate" (Angers. Musée), chanoine l'nsFal. "Deux epitaphes carolingiennes découvertes a Angers" Bull. Comm. Trar. histor. Archeol. 19(90), p. :201.

37. A. DF Cacvovt. "Xouvellas archeologiques". Bull. monum., VI. 16.10. p. 109-110 : "Quicumque legeretis istas litteras. oret pro illon.

3x. ․ Cikay. "The Paleography of Latin Inseriptions in the Eighth. Ninth and Tenth centuries in Italy", Papers Brit. School at Rome. XVI. 191X. n" 10.4. p. 117: "Qui hunc legitis. orate pro me".

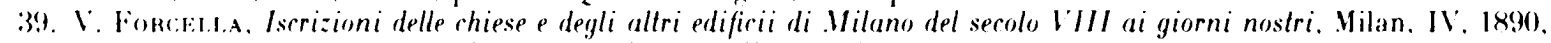
n" 136. p. 101-105: "pro ipso dignas [ Deo precess fundere dignemini"

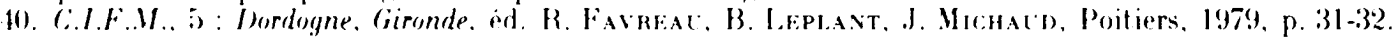

11. C.IF.M. 12: Lude, Ilerault, edd. In.. Paris. 19xx. p. (1). 
à partir du XIII"s. les fidèles se munissent de tout un arsenal de fondations de messes ou d'anniversaires et d'aumônes pour s'attirer la miséricorde du Juge suprême, le "prie pour lui" n'occupant alors qu'une place bien modeste dans l'épitaphe.

De tout temps le chrétien a eu au moment de comparaitre devant le souverain Juge, conscience de sa condition de pécheur. Au vir s. l'épitaphe de Bernard à Toulouse formule la demande de pardon de façon bien lourde : "Que le Pasteur tout-puissant pardonne ce qui doit être pardonné, lui qui pardonne les crimes terribles ${ }^{42}$, et en 1010 la requête de Crescentius à Rome est présentée sur un mode dramatique: "Dis, je t'en prie, dis avec des larmes, en ta miséricorde, Jésus, épargne ton serviteur" ${ }^{43}$. La formulation est, cependant, généralement plus brève: parce Redemplor, miserere Deus, miserere mei, memento mei. Le miserere mei Deus a sa source dans le psaume LI(L), 1, l'un des psaumes de pénitence: "Pitié pour moi, ô Dieu, en ta bonté, en ta grande tendresse efface mon péché». Dic : Miserere Deus trouve-t-on ainsi en 854 à la cathédrale de Bénévent, en 876 à Bazouges, fin IX"s. à la cathédrale de Moutiers-Tarentaise, en 1028 à Santa Maria in Aracoeli à Rome, après 1048 à Saint-Victor de Marseille, ou encore : Dic : Miserere mei ou sui, à Saint-Jean de Latran à Rome en 1003, aux Jacobins de Toulouse en 1270, à Evron en 1277, à Béziers en 1287. L'appel à la miséricorde divine prend une belle forme trinitaire à la cathédrale de Trèves au XIII"s. pour l'épitaphe de Cunon:

\section{SISTE (GRADUM, OLI PERTRANSIS, MEMORARE, ET IIC : O PATER IN CELIS, MISERERE. o GEVITE INGENITI PATRIS, MISERERE-: O PIE SPIRITLS AMBORL M, MISERERE_.-}

Le memorare renvoie évidemment au Memento du canon de la messe, ou il est fait mémoire des défunts pour qu'ils obtiennent le lieu du repos, de la lumière et de la paix, et à la requête du bon larron sur la croix : Domine, memento mei. Ce memento mei se trouve dans des épitaphes des $1 \mathrm{x}^{\text {e }}$. $\mathrm{XII} s{ }^{45}$. Plus souvent on trouve memor sis $^{46}$, sit, esto, estole. expressions fréquentes dans les psaumes, dans le Nouveau testament, chez Fortunat, Alcuin. Micon, Raban Maur, Baudri de Bourgueil, etc.

\section{SIS MEMOR HEC FLERE RECITALS PRO SE MISERERE IT PRESENS SIT EI (ILORLA ST MMA IOEI.}

demande doña Sancha au monastère de La Vega à Oviedo en 129147. Cet appel à la miséricorde divine sexprime aussi au XIII" s. par la formule per misericordiam I)ei ou de très nombreux : "Que Dieu en ay marcy", "que Diex li face pardon".

La finalité de la prière pour le défunt, c'est qu'il repose en paix, requiescat in pace. I'où les nombreux Vivas in Den des premières inscriptions chrétiennes, la finale de l'étonnante déploration de Calandronius pour sa jeune cousine Maura à Beja (Portugal) en 665: Oro Ieum ut sibi det requiem sempilernam ${ }^{48}$, le det ei Dominus vilam sempiternam en Poitou ${ }^{49}$ ou le donet illi vitam sempiternam en Aragon au $\mathrm{XI}^{*} \mathrm{~s}^{50}$, et les innombrables anima ejus requiescat in pace.

42. C.I.F.M.. 7 : Ville de Toulouse, op. cil., n" 40, p. 76: "Parca parcenda qui parcit crimina dira".

43. A Saints-(ome-et-I)amien: "I)ire, rogo, dic lacrimis...".

4.4. Die christlichen Inschriften der Kheinlande, II, op. cil., n"35:2, p. 171.

45). A Saint-Remi de Reims en $8 \times 2$, a Cermigny-des-Prés au début du $1 x^{\prime \prime}$ s.. a saint-I)enis en 1144.

46. On trouve a la fois miserere mei ef memor sit tui dans le psaume VI, un autre des psaumes de: la penitence

47. Vigul. 1slurias monamental .... p. 1 18-15l.

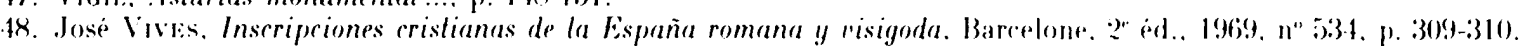

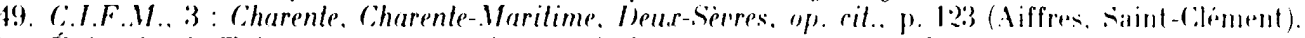

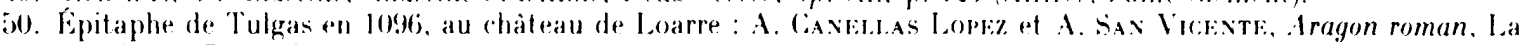
Pierre-qui-lire, 1971, p. 214 
L'épitaphe a encore fréquemment pour fonction de rappeler à chacun la précarité des choses d'icibas et de l'exhorter en conséquence à se bien conduire pour préparer au mieux le passage décisif vers Dieu. Cette leçon morale traduit généralement la volonté du défunt. Dans son testament, en 1294, Godefroi de Landri, chanoine de Saint-Pierre de Lille. demande que sur son tombeau soient inscrits les deux vers suivants:

\section{SL M QLOD ERIS, QLOI ES IPSE FLI; METAMORPHOSIS ISTA WL:VIDANIS REBI'S SI BIDERE COLLA VETAT, \\ Je suis ce que tu seras. ce que tu es, je le fus moi-mème; ce changement interdit de se soumettre aux choses de ce monde ${ }^{51}$.}

Jean Renard, chanoine de Noyon, mort en 1521, avait copiè dans la cathédrale de Noyon une épitaphe très ancienne, gravée sur une pierre tombale. et il avait recommandé de l'inscrire sur son propre monument.

\section{QLISOUIS ADES, QU I MORTE CADES, STA, RESPICE, PLORA. \\ SL M QIOI) ERIS, MODICL M CINERIS, PRO ME, PRECOR, ORA.}

Qui que tu sois qui te présentes. toi qui es sujet a la mort, arrête-toi, regarde. pleure. Je suis ce que tu seras, un peu de cendre, je t'en supplie, prie pour moi ${ }^{52}$.

Ces deux vers, à la réserve que le modicum cineris est habituellement remplacé par quod es ipse fui, se trouvent aussi bien en France qu'en Espagne (Las Huelgas, 1194), en Italie (Rome, Saint-Jean de Latran, XII" s.), en Suisse (Saint-Lirsanne) ${ }^{53}$. Lne autre formulation, très fréquente dans le sud de la France ${ }^{54}$ _ mais on la trouve aussi au-dessus du tombeau de saint Gonzalve au cloître de Silos et dans une épitaphe de Ripoll en 12:3455 -- est la suivante:

\section{QLI TEMLLUM CERNIS CIR NON MORTALIA SPERTIS TALI NAWOLE DOMO CLALITTLR OMNIS HOMO}

Toi qui vois ce tombeau, pourquoi ne méprises-tu pas ce qui est mortel, car tout homme sera enferme en une semblable demeure.

Devant la mort à quoi servent naissance, honneur, richesse, gloire du monde:

VIVERE, QI III PROIDEST? QLII) HONOR, QLII) (GLORIA RERLM?

(rouleau de Vital, abbe de Savigny, 1122) $)^{56}$;

SEI QLII HONOR, QI ID OPES, QITI) GLORLA SANGLINIS ALTI?

(épitaphe d'Aliénor de Vermandois. 1213, à Longpont) ${ }^{57}$ :

QLII) LAIS, QIII) PROBITAS, QIII) HONOR, QI II) FORMA, QLII) ARTES?

(epitaphe de labbe Richard a Saint-Martin de Treves, avant 1238)

51. Karl Baген. Das mittelallerliche Grabbild. Figürliche Grabmäler des 11. bis 15. Juhrhunderts in Europa. Berlin/New York. $1976,1,349$.

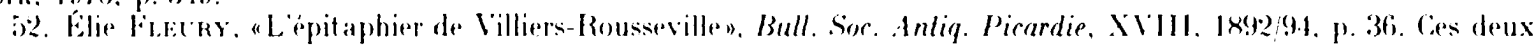
memes vers se trouvent aussi dans une epitaphe de la cathedrale d Amiens (Bibl. nal. fr. K2:2x. p. 31).

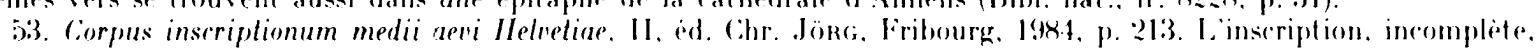
peut ètre restitué alece une quasi-certitude : "[Quisquis ades qui] morte cardes, sta. respice plora

[sum quod eris, youd es ipse ou - ante -... fui] pro me, precor. ora."

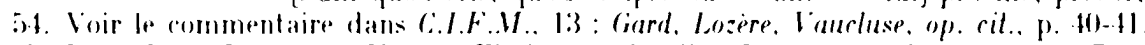

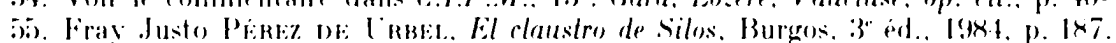

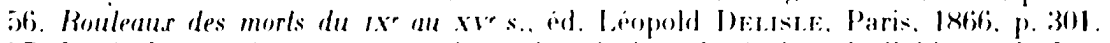

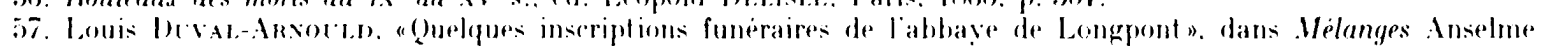
Jivier. t. II. col. t. p. fixt.

ix. Jie christlichen Inschriflen der Rheinlande. n"36it. p. 176. 
GLORLA, QLTID GENERIS, QLTD HONOR, QLID COPLA PRODEST?

IN .MOICLIM CINERIS LABITLR O.MNE QLOD EST

(épitaphe de Fernando à Oviedo en 1267, de Didacus a San salvador de Grandas en 12977)

La vie est brève, l'homme retournera à la poussière. Il faut donc mépriser ce qui passe pour s'attacher à Dieu. On pourrait ici composer une belle anthologie de méditations épigraphiques sur la mort. Je n'en retiendrai que trois, de dates et de pays différents. Voici d'abord l'épitaphe de l'archevèque Frédéric à Saint-Alban de Mayence au milieu du x" s. :

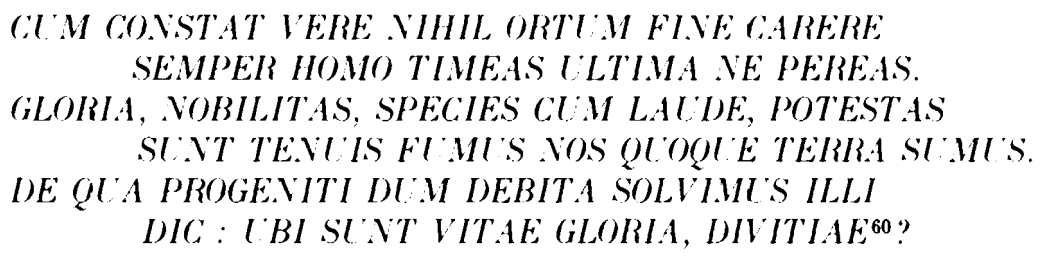

Cne des épitaphes composées pour saint Anselme au début du XIr"s. a le mème ton empreint plus de stoïcisme que de foi chrétienne :

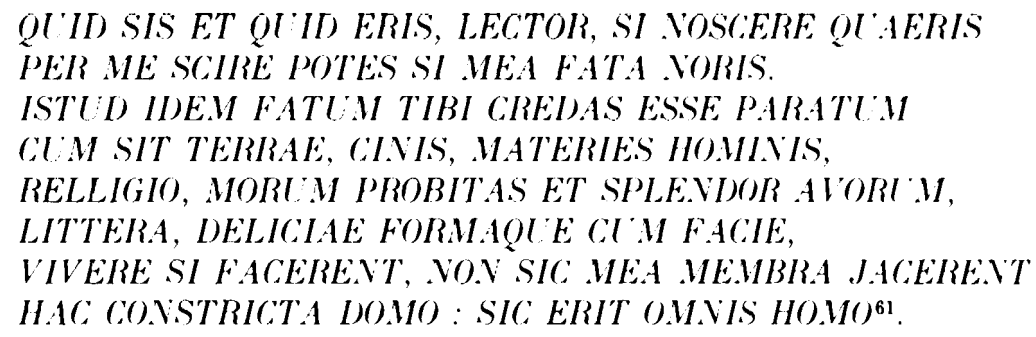

Mème ton dans l'épitaphe du sacriste P'ierre au cloitre de la cathédrale d'Oviédo en 12:52?.

$$
\begin{aligned}
& \text { O TL OUI TRANSIS, MORTALIBLS ADIJTES AN SIS, } \\
& \text { TECT M IISCERNE CITO PRETEREI NCIA SPERTE } \\
& \text { MORS INIDISCRETE MA.JORA MINORIBIS EOIAT } \\
& \text { OMNLA MOHS EQLAT CONIICIONE NECAT }{ }^{62} \text {. }
\end{aligned}
$$

La conclusion est évidente : Homme, pourquoi vis-tu dans le mal, puisque tu sais par expérience quelle récompense est préparée pour le juste et quel chàtiment pour le méchant? Corrige ta vie en effaçant tes péchés dans tes larmes" ${ }^{63}$.

Un nombre relativement élevé d'inscriptions ont pour fonction d'assurer la publicité de différents actes publics ou prives. Lorsqu'on étudiera la façon dont les décisions des autorités étaient portées à la connaissance du plus grand nombre, l'annonce faite à la grand-messe dominicale ou le cri du héraut aux lieux les plus fréquentés de la ville auront sans doute la premère place. Mais le recours à l'épigraphie occupera dans une étude d'ensemble un chapitre de premiere importance. L'inscription ne remplace pas la charte ou la bulle, mais elle lui assure la publicite et, par l'emploi d'un matériau plus résistant qu'un parchemin, la durée. Le préfet de Rome Turcius Apronianus

59. Virill. Aslurias monumental.... p. 41 et 393.

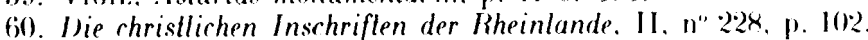

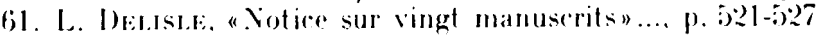

652. Vicit. Aslurias momumental.... p. 37.

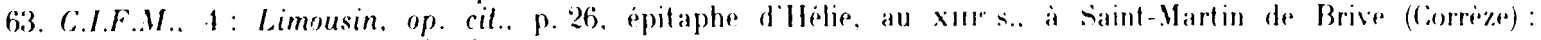
"... corrigeres vitam in lacrumis delendo reatus". 
en avait bien conscience lorsqu il faisait graver sur la pierre un édit, avec ce préambule : «Bien que les actes contiennent l'état de cette décision, il a paru bon de faire afficher cette table qui publie (publicaret) l'ordre des choses, pour en garder une plus complète mémoire" (ad fidem gestorum plenius memorie tradendum), et le texte d'une longue donation gravée au moyen àge sur deux tables de marbre à Sainte-Marie-Majeure à Rome se termine par cette mention : "Ce texte copié sur des documents authentiques a été gravé sur ces marbres pour plus de sécurité et à l'attention des temps à venir" (firmilate temporum fulurorum) ${ }^{64}$.

La Rome antique connaissait bien cette pratique de l'inscription sur pierre ou sur bronze d'actes publics ou privés, et tel diplôme de l'empereur Galba en 68, gravé et expédié à ses destinataires, avait été "copié et vérifié d'après la table de bronze qui se trouve fixée à Rome, sur le Capitole, sur l'autel de la gens Julia" ${ }^{65}$. Il en alla de même à Byzance, témoin cet édit du $x^{*}$ s. ordonnant de planter des cyprès dans les cimetières, gravé sur pierre et conservé en la salle des antiquités chrétiennes au Musée des antiquités d'Istanbul. Dans la chrétienté occidentale aussi, nombreuses furent les inscriptions destinées à assurer la publicité à différents actes concernant villes, églises, communautés d'habitants, etc.

Certaines de ces inscriptions assurent la publicité d'actes particulièrement solennels. C'est le cas des privilèges concédés en 1111 par l'empereur Henri $V$ aux habitants de la ville de Spire, à la requête de nombreux évêques et princes : l'acte fut gravé, en lettres d'or, sur les portes de la cathédrale de spire, avec la représentation de l'empereur "afin que cette concession demeure ferme et intacte en tout àge" (rala et inconvulsa omni aevo permaneal), et "en perpétuelle mémoire du privilège" (in perpetuam specialis privilegii nostri memoriam). Henri V lui-même avait ordonné de graver cet acte sur les portes de la cathédrale, et la confirmation du privilège par l'empereur Frédéric $I^{\text {er }}$ en 1182 fut elle-même gravée sur une table au-dessus de la précédente, avec également une représentation de l'empereur ${ }^{66}$. Ce fut aussi sur la porte de bronze de la cathédrale de Mayence que fut gravé le texte des privilèges concédés à la ville par l'archevêque Adalbert en 1135 , transcription intégrale du texte, en deux parties, occupant quatre-vingt-une lignes ${ }^{67}$. On a retrouvé, il y a une vingtaine d'années, à la cathédrale de Ferrare, la majeure partie de la transcription épigraphique des statuts de la ville en date de 1173, là encore avec un texte complet ${ }^{68}$. L'acte peut cependant, dans sa forme épigraphique, être réduit à une courte notice, tel le privilège accordé, en 1184, à la ville de Worms par l'empereur Frédéric ${ }^{\text {er }}$, qui fut résumé en quelques vers sur une plaque de bronze à la porte de la cathédrale, l'essentiel tenant en une ligne :

\section{A CEVSL CAPITLM SIS LIBERA MUNERE NOSTRO ${ }^{69}$.}

En France trois petites villes du Sud-Est ont gardé ces "chartes lapidaires" qui témoignent encore aujourd'hui des privilèges qui leur furent accordés par leurs seigneurs à la fin du XII' et au début du XIIr" s. Aimar de Poitiers, comte de Valentinois, avait octroyé à ses hommes de Crest une charte d'affranchissement qui fut jurée en 1181 en l'église Notre-Dame en présence de l'évèque de Die et de nombreux témoins; le texte fut gravé sur pierre et apposé à la porte de l'église de Crest du còté de la place. En 1198 Géraud Adémar et son cousin Lambert concédaient une semblable charte aux habitants de Vonteil, depuis Montélimar, et l'acte gravé sur une belle table de marbre était placé sur les remparts, d'où il fut transporté, en 1825, à l'Hòtel de ville. Les franchises

64. Textes cites par A. Drioyr. "Des chartes lapidaires en France ». Bibl. Ec. des Chartes, 2" s., III, 1846, p. 36 et 38. 65. Raymond Biocin. L'épigraphie latine. Paris. 1952. p. 92-93.

66. Die christlichen Inschriften der Rheinlande. II. n" 152, p. 70-73.

67. Die Inschriften der Sladt Mainz won frühmillelalterlichen Zeit bis 1650, par F. V. Aress et K. F. Bauge, Stuttgart, 1958, n" 10. p. 10-17 (Die deutschen Inschriften, 2. Heidelberg Reihe, 2).

68. Adriano Fravcrschivi, I frammenti epigrafici degli statuli di Ferrara del 1173 venuti in luce nella caltedrale, Ferrare. 1969. p. 11-12.

69. A. (ilny, Manuel de diplomatique, Paris, 1893. p. 501. 
accordées en 1244 aux habitants d'Étoile par Aimar, fils du comte de Valentinois, ont été transcrites sur une longue table de marbre qui fut placée au-dessus de la porte latérale nord de l'église du lieu ${ }^{70}$. C'est à la porte Saint-Fiacre à l'entrée du vieux pont qu'était placée l'inscription lapidaire qui énumérait les concessions de Thibaut $V$ comte de Blois et de sa femme à leurs sujets à la fin du $\mathrm{XII}^{\prime} \mathrm{s} .{ }^{71}$. On peut classer dans ces mèmes actes publics concernant les villes l'inscription de 1275, au musée de Viterbe, qui rend compte de la paix conclue après des troubles en la ville et son district ${ }^{72}$.

Bien entendu les privilèges ecclésiastiques, les concessions ou donations obtenues par les églises ont aussi fait l'objet de transcription épigraphique. Dans le mur du chœur de la cathédrale d'Arras on pouvait encore au xvir' s. voir gravée la charte par laquelle Philippe Auguste accordait la régale à cette église ${ }^{73}$. Sur une table de plomb était transcrite en l'église cathédrale de Tours la bulle du pape Innocent III qui confirmait la soumission de l'èvêché de Dol à l'archevèché de Tours ${ }^{74}$. Dans le cloître de Saint-Jean de Latran à Rome on peut voir la transcription sur pierre de la bulle du pape Grégoire XI proclamant la primauté de la basilique du Latran (23) janvier 1372), primauté réaffirmée par une bulle de Sixte IV de juin 1475 également transcrite intégralement sur pierre; dans le premier document la bulle est même dessinée recto et verso ${ }^{75}$. Les inscriptions relatives aux droits des églises sont particulièrement nombreuses à Rome. Grégoire le Grand avait fait graver sur deux tables de marbre les legs considérables qu'il avait faits à l'église Saint-Pierre ${ }^{76}$. Sur une colonne est gravée l'intervention du pape Léon au $\mathrm{X}^{r} \mathrm{~s}$. contre ceux qui s'attaquent aux biens et aux droits de Saint-Paul-hors-les-Murs ${ }^{77}$. A Saint-Jeanet-Saint-Paul on a écrit sur une table de pierre la liste des biens (fundi) de l'église vers le $\mathbf{v i I}^{\mathrm{e}} \mathbf{s}$., état que le pape Grégoire VII a confirmé au $\mathrm{XI}^{\prime \prime}$ s. en y ajoutant un nouveau domaine sans doute acquis dans l'intervalle ${ }^{78}$. A Santa Barbara de' Librari ce sont deux particuliers qui renoncent à tout droit sur l'église au $\mathrm{XI}^{4} \mathrm{s.}^{79}$ et la liste complète serait longue pour Rome ${ }^{80}$. En Espagne, la fondation et la donation de l'église San Salvador de Fuentes dans les Asturies au début du $\mathrm{XI}^{{ }^{*}} \mathrm{~s}^{8}{ }^{81}$, ou de l'église Santa María de Iguacel en Aragon en $1072^{82}$ ont fait l'objet d'inscriptions commémoratives qui affirment en même temps des droits précis de propriété. En France on peut citer, parmi d'autres documents épigraphiques, la concession par Pépin le Bref à l'église SaintGermain-des-Prés du fisc de Palaiseau ${ }^{83}$, une donation faite par un particulier à l'aumônerie de Pierrelatte vers $1100^{84}$, ou celle du lieu d'Aiguebelle consentie par un seigneur aux moines de Morimond pour y construire une abbaye en 113785. Ces transcriptions épigraphiques ne sont pas

70. Ces chartes, étudiées notamment par A. Deloye et P. Ieschamps, seront publiées dans le volume 16 du C.I.F.M.

71. A. Deloye, op. cit., p. 32.

72. Attilio Canosi, Le epigrafi medievali di Vilerbio (secr. VI-XV), Viterbe, 1986, n"28, p. 82.

73. . Nouveau traite de diplomalique. par dom Toestais et dom Tassin, Paris, II, 1755, p. 536, n. 1.

74. A. Drioy e op. cit., et dom Morice, Mémoires pour servir de preuves à l'histoire ecclésiastique el civile de Bretagne, I, Paris, 1742, col. 733-768.

75. Ph. Laukh, Le palais de Latran. Étude historique el archéologique. Paris, 1911, p. 268-269 et 291.

76. . Youveau traite de diplomatique. op. cil.. II. p. 536. n. 1.

77. Angelo Sulvagi, Monumenta epigraphica christiana saeculo XIII antiquiora quae in Ilaliae finibus adhuc exstant. I. Roma : pars 1: Inscripliones cerlam temporis notam exhibentes, Rome, 1943, pl. 38. n" 5.

7x. P. (iermano Dis. Stranisian, La casa celimontana dei SS martiri Giovanni e Paolo. Rome, 1894, p. 479-483, fig. 79 et 80 ; - In.. "Chartes lapidaires de l'église Saint-Jean-et-Saint-Paul a Rome», Bibl. Ec. des Chartes, XXXIV, 1873 , p. $260-266$.

79. Mariano Arumiloni, Le chiese di Roma dal secolo IV al XIX. nouv. éd. par Carlo Ceccheld, Rome, 1942, p. 501.

80. Enrico IDonato, Le carte lapidarie di Roma. Citla di Castello, 1912 (catalogue de 111 numéros de Jean II à Pie IX. dont 19 entre Charlemagne et Boniface VIII qui en 1306) donne une indulgence d'un an à qui visitera Saint-Pierre lors du jubilé par lui institué).

81. Vigll. Asturias monumental... p. 590-592.

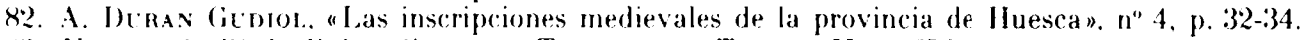

X:3. Vouneau traile de diplomatique. par Totostas et Tassis. II. p. 6533.

84. A. Dreoyr. op. rit.. p. 39-42 et 548

85. (jallia christiana. I. col. 737. 
nécessairement gravées sur pierre. La donation de six livres annuelles et son assignation par le pape Innocent III a Subiaco ont fait l'objet d'une bulle, qui a été peinte en l'église inférieure du Sacro Speco avec un portrait du pape, et ce sont sur deux "tapisseries» du XII" s. qu'avaient été figurés, avec accompagnement d'inscriptions, les donations et privileges dont avait bénéficié l'abbaye alsacienne de Murbach. dans l'ordre chronologique, auteurs des concessions et abbés groupés deux par deux, du comte Eberhard et de saint Léger à l'empereur Henri IV et à l'abbé Erlolfus ${ }^{86}$.

On a eu recours au témoignage, public et durable, de l'inscription, pour des privilèges, franchises. obligations, droits de toutes sortes. L'affranchissement. a la fin du XI" s., du serf Lethert par l'évêque d'Orléans, Jean I"r et Albert, vassal de l'église Śante-Croix, a été gravé à gauche de la porte principale de la cathédrale ${ }^{87}$, où l'acte avait sans doute été passé, conformément à l'usage établi par les constitutions impériales. Cne inscription de 1095. placée a la porte de "Sonsa". rappelait que l'empereur Henri IV avait concédé la liberté à tous les hommes qui viendraient habiter la ville de Viterbe ${ }^{88}$. Aux trois portes de la ville de Blois, avant 1102 , on avait grave la notice d'un accord selon lequel le comte Etienne, la comtesse Adèle et leurs hérit iers s'engageaient à ne pas exiger des habitants le droit de butagium a perpétuité, à condition que ceux-ci construisent un mur d'enceinte pour le château ${ }^{89}$. Ieux inscriptions de Boppard en Allemagne, du xur s., rappelaient des exemptions accordées en contrepartie de la construction d'une tour et de l'entretien du rempart ${ }^{90}$, une exemption de péage était encastrée à l'extérieur de l'église du Sauveur a Duisbourg pour les habitants tenus de participer aux fortifications ${ }^{91}$. A la porte de saint-Denis à Reims une inscription du xur s. faisait savoir que les habitants des villages des environs, Courcelles, Ausson, Vrigny, Trinqueux, avaient fait cette construction, comme ils y étaient tenus, en échange de quoi ils neétaient sujets a aucune coutume à titre de prévoté ou de péage ${ }^{92}$. Ies tarifs de péage faisaient aussi l'objet d'inscription à Trèves, en Anjou au $\mathrm{xI}^{\prime \prime}$ s. ${ }^{93}$, et a la mème date une inscription notifiait - nolum sil omnibus quod - que tous les habitants de Duisbourg passant à Coblence devaient acquitter le péage ${ }^{94}$. (On avait aussi recours à une grande inscription, placée a la porte principale de la cathédrale de Trèves, pour faire connaitre les privilèges que les archevèques de Cologne et de Trèves avaient accordés aux marchands de Cologne an XiI" 5.95 .

Les inscriptions etaient encore utilisées pour marquer des limites. A l'ancien évêché de Die une inscription en langue vulgaire, du XnI" s., faisait savoir - sapiant tuil cil que sunt - que le mur en question était mitoyen ${ }^{96}$. La stèle de Konin en Pologne atteste qu'en 115 l elle marquait le point médian du chemin entre Kalisz et Kruszwica et cinq bornes du xul" s. matérialisaient les limites. en silésie, de la juridiction des évèques de Breslau, termini sancti Johannis ${ }^{97}$. De mème à

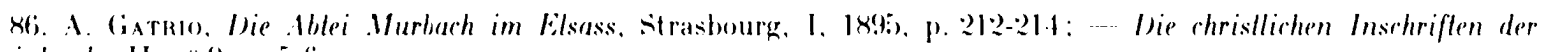
Rheinlande. II, n"9, p. 5-6.

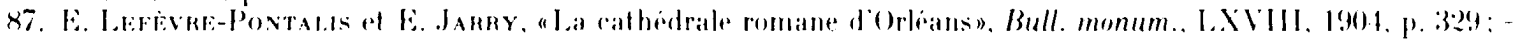

Tolstame thasin. II. pl. 2x et p. fizl.

Xx. A. Carosi. op. ril., p. :(1)-2.)

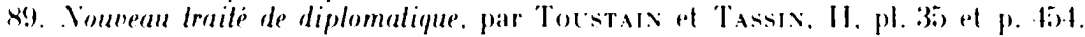

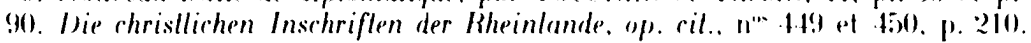

91. Ithid.. I" 6itx. p. '997.

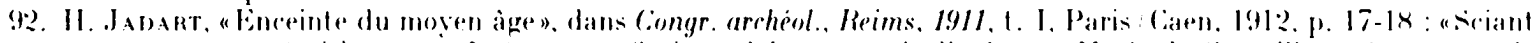
quam presentes tam posteri hoc opus factum esse fierique debere a ruricolis sancte Varie de Curcellis et dussomno, de Verniaco cum Tencauda, nec aliam ab eis prepositura vel teloneo consuetudinem exigendamn.

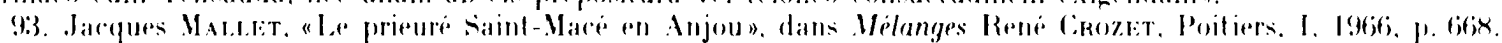

9. I He chrisllichen Inschriften der Bheinlande. II. n" 4.4. p. 211.

(5). Hid.. n"3:1, p. 170.

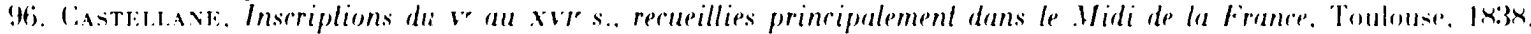
p. 27) [lecture rorrigese d'apres photo].

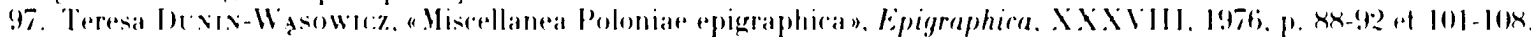


Heppenheim une grande inscription sur pierre donnait les limites de l'église à la date de $805, \mathrm{Hec}$ est terminatio istius ecclesie ${ }^{98}$.

Cette fonction publicitaire d'actes publics ou privés fait que bon nombre des inscriptions de cette catégorie emploient des expressions propres à la diplomatique. File marque bien aussi la différence entre actes diplomatiques et inscriptions. Les premiers fondent des droits, les secondes ont seulement pour rôle de rappeler ces droits et de les faire largement connaitre à tous, sans avoir en elles-même de valeur juridique.

III

On peut mettre à part, dans l'épigraphie médiévale, les inscriptions commémoratives qui, à l'instar d'annales ou de chroniques, ont pour fonction de rappeler un événement. C'est une fonction qui est de tous les temps, témoins, parmi mille exemples, deux inscriptions de 1889 sur la façade de l'hôtel de ville d'une petite commune du Quercy rappelant le centenaire de la Révolution ${ }^{99}$, ou la plaque laissée sur la lune par les hommes qui y posèrent pour la première fois le pied en $1969^{100}$. Trois inscriptions commémorent la construction, au temps du pape Léon IV au milieu du $\mathrm{IX}^{\circ}$ s., d'un mur d'enceinte autour de la basilique Saint-Pierre de Rome ${ }^{101}$. Dans la salle basse du clocher de Daumazan-sur-Arize une inscription lapidaire indique qu'«en l'an mil cent moins un, alors que déjà Phoebus avait promené sa lumière quinze fois en juillet" les Francs avaient pris Jérusalem ${ }^{102}$. Les travaux de construction de l'église Saint-Gilles-du-Gard ont commencé le 3 avril 1116 , nous dit une inscription à l'extérieur de l'église ${ }^{103}$. L'église de Willich a été construite en 1146, année de grande pénurie pour les céréales ${ }^{104}$. On trouve à Aguilar en Castille plusieurs inscriptions d'achèvement de travaux ${ }^{105}$. A Rome est indiquée à la façade de Santa Maria sopra Minerve la hauteur atteinte par une crue du Tibre, ce qui se trouve aussi noté en 1277 sur un mur de la via del Banco di S. Spirito ${ }^{106}$. Au clocher de la petite église poitevine d'Haims est gravé :

\section{L'AN DE GRACE M CCC XXXIX FUT FET IDE TOMBES, FET FUT DE TOMBES CET CLOCHER.}

Mais, au moins pour les documents épigraphiques qui nous sont parvenus, les inscriptions sont rarement seulement commémoratives. La célèbre broderie de Bayeux est bien la représentation figurée de la conquête de l'Angleterre par Guillaume le Conquérant, et les inscriptions qui l'accompagnent ne sont que descriptives. Pourtant une croix est tracée lorsque le duc Guillaume est figuré pour la première fois, et une autre croix lorsqu'il s'embarque pour l'Angleterre. Document commémoratif, certes, mais aussi extraordinaire réalisation "publicitaire» à la gloire du Conquérant, avec une présentation des faits qui justifie son intervention. Le plus souvent les

98. Die christlichen Inschriften der Rheinlande, II, n"193, p. 187.

99. A Calus (Lot) : “5 mai 1889. Centenaire de la première séance des Etats généraux qui délivrèrent le peuple de la servitude des seigneurs, proclamèrent l'égalité des droits et la fraternité humaine"; "14 juillet 1889 . Centenaire de la prise de la Bastille, prison forteresse du despotisme où l'on enfermait sans jugement les défenseurs du peuplen.

100. "Here men from the planet Earth first set foot upon the Moon july 1969 A.l.. We came in peace for all mankind" (avec les signatures des trois astronautes et du président des États-linis).

101. O. Marucchr, Elements d'archéologie chrétienne. Notions générales, Paris/Rome, 1899, p. 252-253.

102. C.I.F.M., 8 : Ariège, Ilaute-Garonne, Haules-Pyrénés, Tarn-el-Garonne, éd. R. Favreau, J. Michaun, B. L.epiant, Paris, 1982, p. 8.

103. Ibid., 13 : Gard, Lazère, Vaucluse, op. cit., p. 70.

104. Die christlichen Inschriften der Rheinlande. II, n" 624, p. 288.

105. Miguel Ángel Garcia Gerve, El arte romanico en Palencia, Palencia, 1961, p. 189 et 254: inscriptions de 1041. 1209 (au Musee archéologique national a Madrid), et 12133.

106. V. Foncert. A, Iscrizioni delle chiese e di altri edificii di Roma dal sec. XI ai giorni nostri, XIII, Rome. $1879, \mathrm{n}^{\prime \prime} 424$, p. 210 . 
inscriptions qui commémorent une réalisation comportent le nom du commanditaire, de celui qui a commandé et financé l'seuvre qui a présidé aux travaux, ou/et le nom de l'artiste qui a réalisé l'oxuvre. Il s'agit. à l’évidence d abord du souci de voir son nom passer à la postérité. Empereurs. grands fonctionnaires, notables avaient souvent eu leurs noms inscrits sur les monuments de l'empire romain. Des les premières inscriptions chrétiennes, rois. évèques, prètres ne manquent pas de rappeler qu'ils ont fait faire une toiture. une mosaïque, une église. une cathédrale, un portique etc... et qu'ils l'ont fait faire à leurs frais, sumptu proprio, suis sumptibus ${ }^{107}$. L'empereur Justin II et sa femme ont leur nom sur la croix. par eux donnée, qui est conservée au trésor de Saint-Pierre du Vatican, la trìs glorieuse reine Theodelinde rappelle, sur la reliure dorlèvrerie qu'elle "offre" a Ylonza, qu'elle a aussi fondé l'église Saint-Jean-Baptiste près de son palais, et sur le trésor de La Fuente de Ciuarrazar on trouve un Reccescinthus rex offert. Ies donateurs peuvent etre beaucoup moins importants. tels Yumma sur la chàsse de Saint-Benoit-sur-Loire, ou l'erigua Flammola a Quintanilla de las liñas. si les mentions de commanditaires sont en général brèves aux premiers sieccles, elles ont par la suite tendance a prendre de l'ampleur. Les travaux réalisés par le pape Yicolas III en 1278, palais, chapelle, maisons, mur d'enceinte du Vatican, sont soigneusement énumérés, le pape est qualifie de sanctissimus pater, ef on indique qu il était romain, de la famille des Orsini ${ }^{108}$. Si l'on considere les inscriptions conservées a Viterbe pour le dernier tiers du xnI" s., qui rappellent la construction d'un aqueduc, d'un mur, de deux tours, et la restauration d'une fontaine. on voit que dans chacune d'entre elles le chef de la cité qui a fait faire ces travaux est nomme avec les plus grands eloges, Raniero Catti, de noble origine (stirps clara), par la gràce de Dieu capitaine de la ville, "prudent". "aimant la paix et cultivant la justicen, Arturo, de noble souche (clara stirpe), capitaine respecte de tous of bienveillant dans sa charge. ou encore noble homme Corrado del Branca, podestat de la cité, honoré pour son heureux gouvernement ${ }^{109}$. Les inscriptions commémoratives peuvent aussi se borner a citer les autorités en place au moment de lévénement, fin d'un pont en 1346 à Savone 110 ou pose de la première pierre d'une tour a Dossenheim en 138: $)^{111}$.

Dans les inscriptions qui fournissent le nom du commanditaire de l'oxure, on peut, en géneral, distinguer une double fonction, garder la mémoire et demander des prières, cette seconde fonction s"imposant a nous du fait que le tres grand nombre de ces inscriplions nous sont conserveres sur des monuments ou des objets religieux. Le pape Pascal I"r (817-824) a laissé son nom a Rome sur les mosaiques de Sainte-Praxede (abside, oratoire Saint-Zénon), de Sainte-Marie-in-I)omnica, de Sainte-técile, et sur le coffret d’argent et le reliquaire en forme de croix conservés au Musée du Vatican. Il espere bien, de ce fait, mériter d'accéder au ciel : Fretus ut his limen merealur adire polorum ${ }^{112}$. Les rois des Asturies ont laissé leur nom et celui de leur femme dans une série d'inscriptions doviedo au $x^{*}$ et au début du $x^{*}$ s. : le prince Ranimire et sa femme la reine laterne, dans une inseription de 8.18 a santa Maria de Naranco, rappellent qu ils ont rénove l'église et demandent quen retour le pardon de leurs péchés leur soit aceorde113. De saint Dunstan, au x" s., on connail une série d'inscriptions de donations, ef sur un manuscrit d'oxford il est represente prosteme aux pieds du Christ ef lui demandant sa protection : Dunstannum

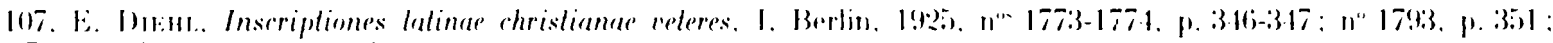
" $179 x$. p. 35:2: n" 1x.1. p. 3633.

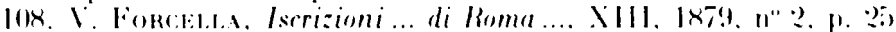

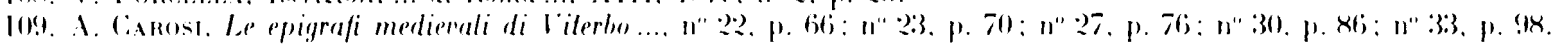

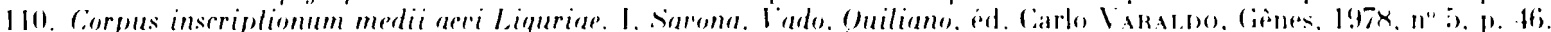

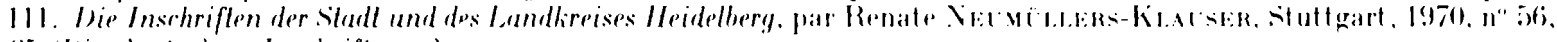

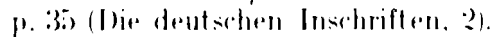

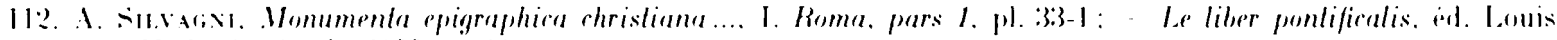

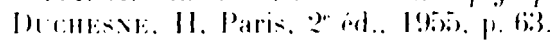

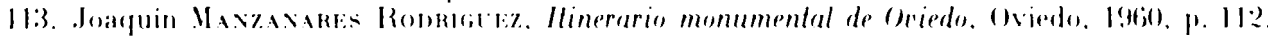


memel clemens rogo, Cihriste, luere14. Liempereur Henri II, lui aussi souvent cité dans les inscriptions qui mentionnent ses donations, en attend très précisément la récompense (merces) céleste ${ }^{115}$. A Hildesheim, en ce mème début du $\mathrm{xI}^{\prime \prime} \mathrm{s}$., le nom de l'évèque Bernward est partout, sur les portes de bronze de la cathédrale, sur un crucifix d'argent, un chandelier, des évangéliaires et un sacramentaire du trésor de la cathédrale. Il demande qu'on se souvienne de lui -- ob monimentum sui - que Dieu voie son ceuvre - cerne Deus - et qu'Il lui soit miséricordieux Sis pia, quaeso, tuo Bernwardo, trina potestas ${ }^{116}$. Au siècle suivant l'abbé Suger, dont nous savons, par ses écrits, la part qu'il prit dans les travaux de saint-Denis, a composé de nombreuses inscriptions, où il fait régulièrement figurer son nom, et il s'est fait représenter au linteau du portail occidental de l'abbatiale, sous le Jugement dernier, agenouillé aux pieds du Christ et lui demandant de le compter dans son troupeau :

\section{SLSCIPE VOTA TLI, JUIDEX DISTRICTE, SUGERI \\ INTER OVES PROPRIAS FAC ME CLEMENTER HABERI ${ }^{117}$.}

La demande de prières, l'espoir de voir leurs libéralités récompensées dans l'au-delà sont fréquemment exprimés dans les inscriptions qui rappellent la part des donateurs même plus modestes. Ces inscriptions sont souvent placées à la vue de tous, et font un appel direct à tous ceux qui pourront les voir. L'inscription de Pantaleon, sur les portes de bronze de San Michele à Monte Sant'Angelo en 1076, en est un bon exemple :

\section{A ROGO VOS OMLES QII HIC VENITIS CALSA ORATIONIS UT PRIIS INSPICIATIS TAM PILCHRLM LABOREM ET SIC INTRANTES PRECAMINI IOMINUM, PRONI, PRO ANIMA PANTALEONIS QLI FEIT ALCTOR HLJIS LABORIS. I O SI MME PRINCEPS MICHAEL, WOS TE ROGAMLS gLI VENIMUS AIORANDIM, TLAM GRATIAM UT WOSTRIS PRECIBLS AUDIAS PRO ACCTORIS HIJUS ANIMA, UT NOBISCLM FRLATIR SEMPITERNA GAUDIA, QII TUI VOMINIS SANCTITAS FECIT IDECORARE TALIA ${ }^{118}$.}

Une inscription qui mentionne la dédicace de la Vera Cruz à Ségovie en 1209 demande que tous ceux qui ont participé à la fondation aient place dans les cieux ${ }^{119}$. Le donateur, au XII" s., d'un pupitre de marbre qui existait en l'église S. Giacomo alla Longara à Rome, "fait savoir à tous ceux qui sont instruits dans l'art de lire" (nolum sit cunctis instructis norma legendi), qu'il a fait réaliser cette cuvre pour la louange de la Vierge et de saint Nicolas ${ }^{120}$. A l'intérieur de l'église Saint-Paul de Narbonne, une inscription nous apprend qu'en 1224 l'abbé Robaldus, venu de Pavie, agrandit l'édifice et fit refaire des toitures effondrées, et elle se termine par une prière pour que le Christ lui donne en récompense (pro mercede) de vivre avec lui au ciel ${ }^{121}$. Le chevalier Pierre de Castelnau, citoyen de Toulouse, qui fait ériger une fontaine à Ramonville-Saint-Agne en 1270, déclare le faire en l'honneur de Iieu et de Marie, «en l'honneur de tout le genre humain et pour la

114. Elzbieta Trupt.e, Anglo-Saron .Manuscripls 900-1066. Londres, 1976, n" 11, p. 41, ill. 41 (A Survey of Manuscripts Illuminated in the Bristish Isles. ed. J. J. (i. Alsxaviere. vol. II).

115. Ambon d'Aix-la-thapelle (I)ie christlichen Inschriften der Rheinlande. II. n" 18.4. p. 224)

116. Francis J. Tscinax. Saint Bermoard of IIildesheim. II. Notre-I)ame Indiana, 1951. p. 125-127. et III. pl. n"104 et 105) (reliure de l'évangéliaire de la cathédrale d'Hildesheim. ms. 18). Voir Wilhelm Bragrs. Die älleren Hildesheimer Inschriften bis zum Tode Bischof Ilezilos (†1079). Göttingen. 1983) (Abhandl. Akad. Wiss. im Göttingen. Philolog.-histor. Ki.., 3" s., 131).

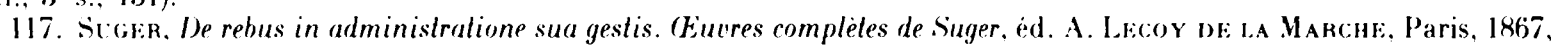
p. 189: - Philippe Vermer. "Saint-Denis et la tradition carolingienne des tituli. Le be rebus in administratione sua de Sugern, dans La chanson de geste el le mythe carolingien. Vélanges René Lol:1s, I, Saint-Père-sous-Vézelay, 1982, p. 344.

118. (juglielmo Matthias. Le porte bronzee bizantine in Mtalia. Rome. 1971. p. X:3.

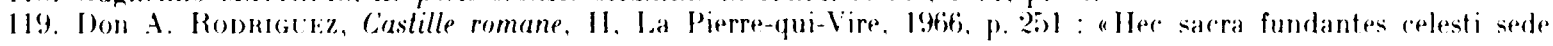
locenturn.

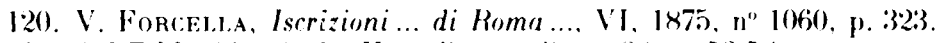

121. C.I.F.M., 12: Aude. Herault, op, rit.. n" 34. p. 53-5.4. 
rédemption de ses péchés» ${ }^{122}$. Pierre de Montbrun. qui fait construire en trois ans la chapelle Sainte- Madeleine à Narbonne (1273-1276), ne manque pas de rappeler sa brillante ascension qui, de camérier du siège apostolique et de notaire l'a mené sur le siège archiépiscopal de Narbonne, et il termine par la requète: (Orate pro eo ${ }^{123}$. Lans l'inscription de fondation de la Maison-Dieu de Viterbe en 1303, placée a l'origine sur la façade de l'ètablissement, le chevalier de la ville qui avait fondé et doté la maison sur ses biens demandait le pardon de ses péchés et la prière des pauvres pour que Dieu ait pitié de son àme et de celle de sa femme ${ }^{124}$. C'est du Memento du canon de la messe ${ }^{125}$ que le donateur des portes de bronze de la cathédrale de Ravello, Serge Musetula, s'inspire en 1179 : dans un premier texte il demande au Seigneur de se souvenir de lui, de sa femme, de leurs deux fils et de leur fille, dans une deuxième prière il demande l'aide du Seigneur pour lui-mème (Memento, Domine, famuli lui Sergii Mussetulae de Jordane) ${ }^{126}$.

Les inscriptions de noms d'artistes se comptent par centaines et sont sans doute plus nombreuses que celles réservées aux donateurs et commanditaires. Elles répondent a la mème double fonction de glorification personnelle. ici-bas et dans l'Au-delà, et de demande de prières. Le plus généralement le nom est donné seul, Benedetto Antelami, maître Nicolas de Verdun, frère Hugues d'Oignies, etc.. avec le seul verbe fecit. La place très évidente réservée au nom peut compenser la brièvelé du texte, par exemple la situation, au milieu du linteau, du : Gislebertus me fecil, sous le magnifique tympan du Jugement dernier à la cathédrale Saint-Lazare d'Autun, ou du : Girauldus fecit istas portas sous le tympan de l'ancienne église Saint-Lrsin de Bourges. La qualité de l'artiste et de son ceuvre est parfois soulignée, ainsi à Toulouse celle de Gilbert, vir non incertus ${ }^{127}$, ou à Autun du moine Martin qui a sculpté dans la pierre une ceuvre d'une admirable beauté, mirabili arte ${ }^{128}$. Mais nulle part autant qu'en Italie, a partir du $\mathrm{XI}^{\prime}$ s., l'importance de l'artiste n'est mise en relief. Il $y$ a d'abord quelques noms très connus. A la cathédrale de Modène, au XII" s., Lanfranc a été maitre d'cuvre:

\section{I.WGEVIO CLARLS LANFRANCTS DOCTLS ET APTIS EST OPERIS PRINCEPS RECTOROLE MAGISTER}

et par l'érlat de sa sculpture Guillaume a mérité d'avoir son épitaphe placée en la façade même de la cathédrale:

\section{INTER SCTLTORES QLANTO SIS IIGNTSONORE CLARET SCLLTCRA VIWC WILLIGEL.ME TI A ${ }^{129}$.}

Aux calhédrales de Ferrare et de Vérone et a San Zeno de Vérone on a la signature de Nicolas. l'habile artiste sculpteur que tous ceux qui verront ses ceuvres loueront par tous les siècles:

$$
\begin{aligned}
& \text { ARTIFICEM GNARE M OLI SCLLISERIT HAEC NICHOLAL M } \\
& \text { HI WC CONCTREETES LATDANT PER SAECILA GENTES }{ }^{330} \text {. }
\end{aligned}
$$

Par la suite, au xuI" s., la louange de l'artiste se complaît dans le superlatif : Jean, civis romanus doctissimus à San Pietro d'Alba, Anseramus de Trani, summus qui sculptor in arte refulsit à Bari,

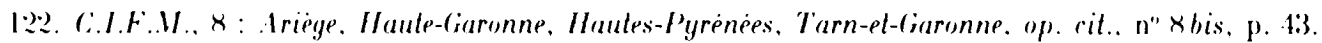

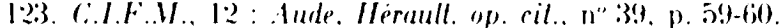

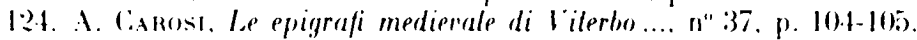

1.5. ".llemento. Demine. famuloram famularumgue Larum ...".

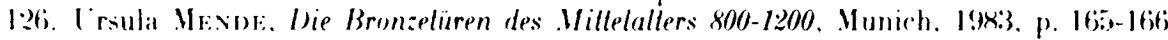

1.27. C.I.F.M.. 7 : lille de Toulouse. op. ril. p. 64.

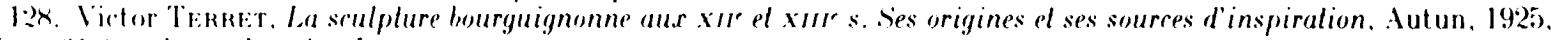
II. p. bl (tombealu de saint Lazare).

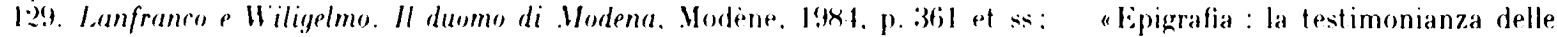

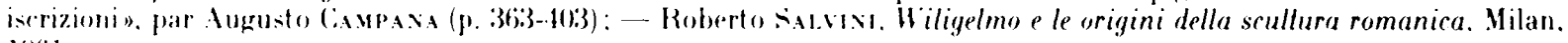
1961.

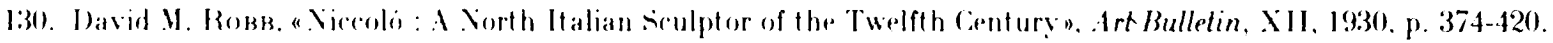


maitre Nicolas, à la docta manus, à la cathédrale de Bitonto, Laurent et son fils Jacques, magistri doctissimi romani, à Cività Castellana, maître Renaud qui à Pise réalise, mire, sollerte, ingeniose, une "ouvre aussi admirable que précieuse", Nicolas de Pise, le sculpteur dont il faut louer "dignement la main si bien instruite» (digne tam bene docta manus). (iui de Còme. à Pistoia. sculpteur doctus in arle, qui doit ètre "loué». Melchior, faber operis laudabilis, à Rapolla. Peregrinus, à Sessa, dont "l'ceuvre est éclatante». Solsternus, à Spolète, doctor ... hac summus in arte modernus, etc. Souvent, dans ces textes, reviennent le verbe laudare, le mot laus, pour altester de la louange qu'il faut réserver à l'artiste ${ }^{131}$.

La fonction de la priere sollicite par l'artiste, en consideration de son ceuve, est beaucoup moins souvent exprimée que dans le cas du commanditaire. Sur la croix d'ivoire de Gunhild, du XI" s., au musée de Copenhague, le sculpteur liutger demande a tous ceux qui ont foi dans le Christ en croix de faire mémoire de lui dans leurs prières ${ }^{132}$. En l'église San Salvador de Nogal de las Huertas en 1063 le sculpteur Xemenus demande simplement: Orate pro eo ${ }^{133}$, et en la petite église de Carennac, sous te porche, on lit: Girberlus cementarius fecit istum portarium benedicta sit anima ejus ${ }^{134}$. Ce sentiment que l'artiste a de l'importance de son cruvre se retrouve dans les manuscrits. un domaine proche de l'épigraphie. Parmi des centaines d'exemples on peut en citer deux particulièrement éloquents à ce sujet. Dans un manuscrit du XII" s., à Cambridge, le scribe et moine Eadwine est portrait ure, avec un dialogue entre le scribe et son ecrit; le scribe dit : «Je suis le prince des scribes, et ni ma louange ni ma renommée ne doivent périr. Ce que je suis, ma lettre le proclame». La lettre répond : "Ton écriture, Eadwine, toi que représente cette figure peinte, te montre vivant, par ta renommée, pour les siécles. La beauté de ce live témoigne de ton génien. Aux dernières lignes se trouve une prière pour que Dieu ait pour agréables le manuscrit offert ef son auteur ${ }^{135}$. Te mème Robert d'Eu, scribe de l'abbaye de Foucarmont, au début du xur" s., ne craint pas d'écrire à la fin du manuscrit qu'il a copié : Scriptor laudetur. Robertus de Augo, el hunc venerelur curia celestis .... cetibus associetur sanctorum ${ }^{136}$. Ces inseriptions célebrant le commanditaire et l'auteur ont des fonctions pour partie comparables a celles des epitaphes : assurer la pérennité du nom, demander des prieres, mais elles sen différencient par la volonté de célébrer l'cuvre, et, par elle, la qualité de celui qui l'a permise ou réalisée.

131. Sur les art istes ef leurs signatures epigraphiques on peut voir, notamment : Artistes, arlisans et production artistique

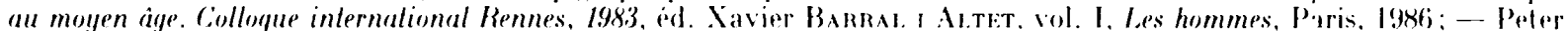

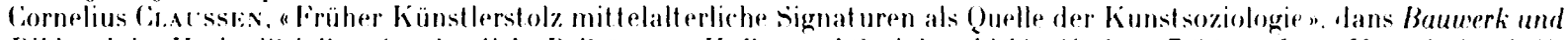
Bildwerk im Hochmiltelaller. Anschauliche Beilräge zur Kullur und Sozialgeschichte. 1981. p. 7-31. - It... „Künstlerinschrif-

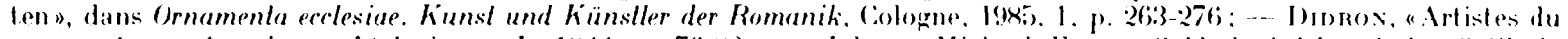

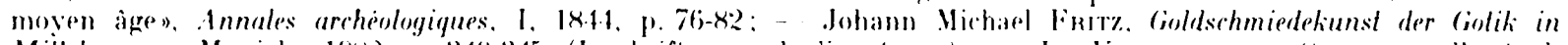

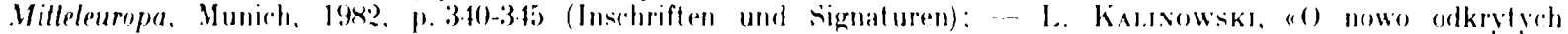

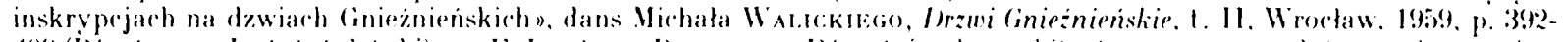

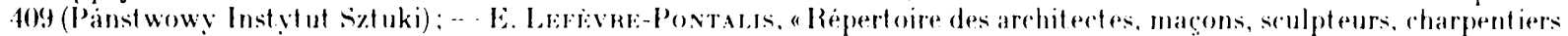

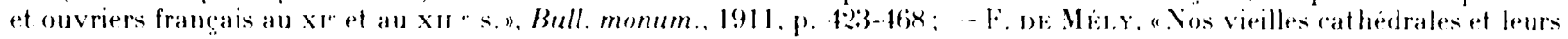

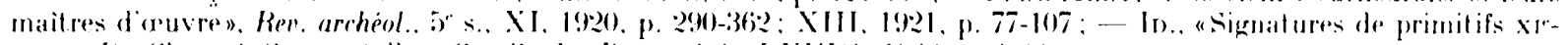

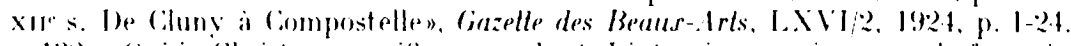

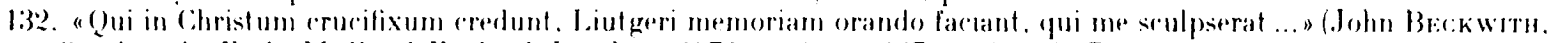

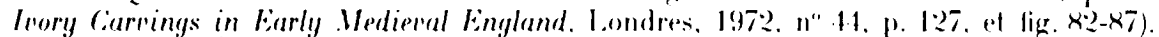

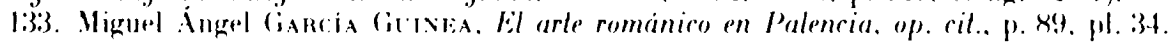

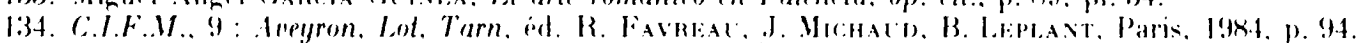

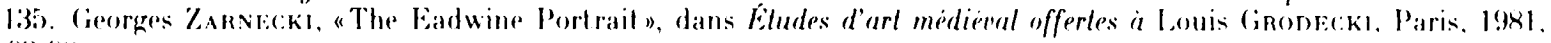
p. 9:3-98.

136. Catalogue des manuscrits en érriture latine portanl des indirations de date. de lieu ou de copisle. par Ch. Savarax ef

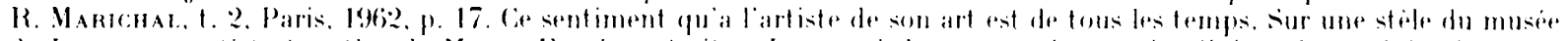

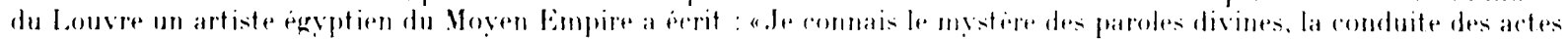

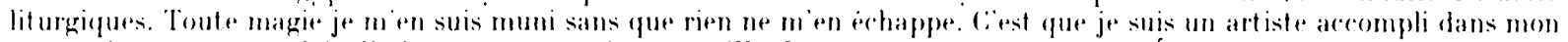

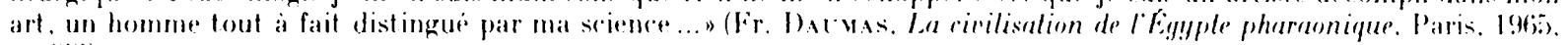
p. 13:3). 
Beaucoup d'incriptions s'inspirent de la liturgie, dont on sait la place essentielle qu'elle tient dans la vie des moines ou du clergé séculier. Quand on se pose la question de déterminer si des inscriptions avaient une fonction particulière dans la liturgie, il semble, de prime abord, que la réponse ne puisse ètre que positive, mais la formulation en est moins aisée que dans d'autres domaines, car cette catégorie d'inscriptions a un caractère moins tranché que d'autres, et les textes épigraphiques offrent moins de renseignements directs sur celte fonction.

On peut naturellement retenir les inscriptions de dédicaces d'eglise et de consécrations dautel parmi celles qui ont une fonction propre dans la liturgie. Ces cérémonies sont particulièrement solennelles, la fète de dédicace fait partie des grandes fètes du calendrier liturgique de chaque église. L'église doit avoir fait l'objet d'une dédicace par un évêque. l'autel avoir été doté de reliques et consacré pour que les cérémonies du culte puissent se dérouler normalement. Il est donc fort important que soient transcrits à la vue de tous les témoignages de ces dédicaces et consécrations, qui en mème temps rappellent la date anniversaire de la dédicace et le nom des saints vénérés dans l'église.

Les inscriptions de dedicace sont très nombreuses, dès les premiers siècles de l'Eglise. Le plus souvent gravées dans la pierre pour leur assurer la durée, elles sont placées à l'extérieur, près d'une porte de l'église, ou dans le chour. Elles renseignent sur le(s) prélat(s) consécrateur(s), la date de la dédicace, le(s) patron(s) de l'église. Quelques exemples seront ici donnés à partir des inscriptions de la province de Burgos. A Villamartín de Sotoscueva est conservé le texte suivant :

SIT PAX INTRANTI, SIT GRACIA DIGVA PRECANTI.

IIII IIUS ALGISTI IELICATA FLIT ECCLESIA SAVCTI STEPHANI,

PER MAVTM IOMINI PETRI, BIRGEVSIS EPISCOPI, WOTO IJE IN

FESTO SAVCTI LALTEVTII, ERA MCCXIII ${ }^{137}$.

Ainsi nous savons que l'église Saint-Étienne fut dédiée le dimanche 10 aoùt 1175 par l'évèque de Burgos, don Pedro Perez, le texte s'adressant au fidèle à qui on souhaite, à son entrée dans l'église, la paix de Dieu, en une formule métrique, dont on trouve d'autres exemples dans l'épigraphie d'Occident à cette époque. Le dimanche "7 novembre 1199 l'évèque de Burgos Marin a dédié l'église Saint-Pierre, au temps de l'abbé Martin», lit-on à droile du portail de la collégiale de Cervatos ${ }^{138}$. C'est à l'intérieur de l'ermitage de san Pantaleón de Losa qu'est fixée l'inscription de "consécration de léglise par l'évèque de Burgos, Garsias, en la première année de son pontificat, le 27 févier 1207"139. L inscription emprunte souvent à la liturgie de la dédicace. Ainsi la dédicace du prieuré de San Frutos par l'archevèque de Tolède en 1100 est précédée d'un Hec est domus Domini qui est un verset plusieurs fois répété dans le commun de la dédicace d'une église ${ }^{140}$. Dans le mur de l'áglise de Neila un texte, du $\mathrm{xI}^{\prime \prime}$-XII" s., est une prière de bénédiction pour l'église et les fidèles qui viendront $y$ prier :

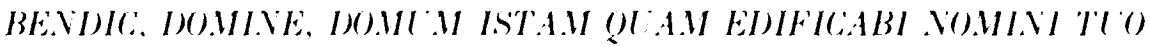

BENIENTIL M IN LOCO ISTO EXAl DI PRECES IN EXCELSO SOLIO

(iLORIE TI E $E^{141}$.

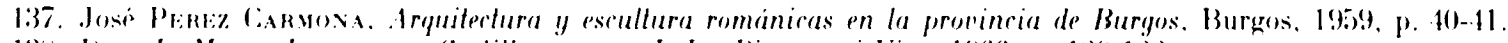

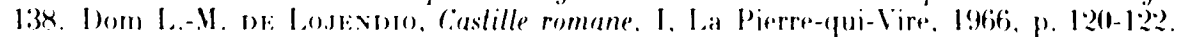

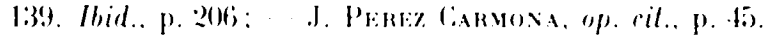

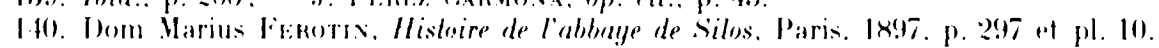

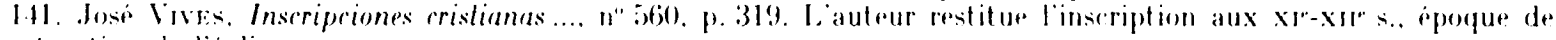
construction de lieglise. 
Là aussi il s’agit d'un texte appartenant à l'office de la dédicace d'une église ${ }^{142}$. (n aurait pu prendre pour exemple les dizaines d’inscriptions très développées conservées dans les églises de Rome pour les $\mathrm{xI}^{-}-\mathrm{XuI}^{\prime}$ s. On y aurait trouve, avec beaucoup plus de pompe, les éléments : date, prélat consécrateur, patronage, fournis à l'intention des cleres et des fidèles. La volonté de garder la mémoire de cette date essentielle est clairement manifestee par l'abbé Suger qui fait inscrire à la façade de son église de saint-Jenis l'année de sa consécration "afin qu'elle ne tombe pas dans l'oublin'143.

Les inscriptions de consécration dautel. gravées ou parfois peintes. ont leur place naturelle dans le chour, le plus souvent sur la lable mème de l'autel. Le concile de Trèves de 1310 ordonnait de placer en chaque église, devant, derrière ou sur l'autel, une image, une sculpture, un texte ou une peinture (imago vel sculptura vel scriptura vel pictura) désignant expressément et manifestant à chacun (cuilibet intuenti manifestans), en l'honneur de quel saint l'autel était établi ${ }^{144}$. Les inscriptions de consécration d'autel sont de facture proche des inscriptions de dédicace, mais l'état des reliques conservées dans l'autel en constitue une partie importante. C'est par dizaines que dans chaque pays on peut relever ces inscriptions et des listes de saints vénérés dans l'église. Le concile de Toulouse de 1590 prescrira mème de tenir dans chaque église des tableaux offrant au public les noms de toutes les reliques qui pouvaient y ètre vénéress ${ }^{145}$. Cette volonté de faire connaître aux fidèles les reliques de chaque église est exprimée dans une inscription du musée de Pavie, de 800 environ, adressée à tous ceux qui viennent (quirumque venitis) en l'église de S. Giovanni in Borgo, pour leur apprendre (discatis) combien grand est le trésor des reliques qui y sont conservées et leur en fournir l'état ${ }^{146}$. ou dans une inscription de 1122 conservée au musée de León : scitole in ea reliquias esse conditas ... "Sachez qu en cette église sont déposées les reliques du Saint Sauveur, de sainte Marie, de saint Pierre, de saint Paul et de tous les saints" ${ }^{147}$ ou encore sur une plaque de marbre située derrière le maitre-autel de l'abbatiale de Condom : "Si tu souhaites. lecteur, connaitre les reliques sacrées conservées ici venere ce lieu orné d'une inscription»"

Les translations de reliques faisaient aussi l'objet ef de célébration liturgique et dinscriptions. Raban Vaur nous en est un précieux témoin. a travers la vie que hui a consacrée Rodolphe Scholastique, son diciple. Raban fait apporter en son abbaye de Fulda les ossements des martyrs Alexandre et Fabien. les fait placer avec grand honneur en l'église Notre-Dame, et y ajoute des vers, écrits en lettres d'or, qui précisent par qui, d'ou et pour qui ces reliques ont été transférées ${ }^{149}$. Cette longue inscription se termine par une adresse aux fideles:

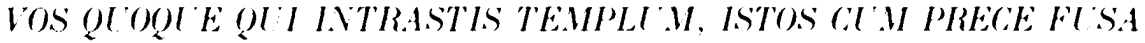 PATRONOS VOBIS OU AERITE IN A'XILIIX.}

De la mème manière Raban porte en l'église Saint-Jean-Baptiste les reliques des martyrs Lirbain et Quirin, et les accompagne d'une inscription de seize vers qui raconte la translation ef se termine par une prière.

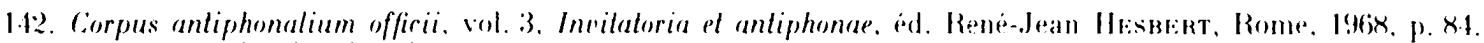

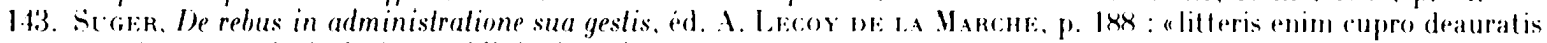

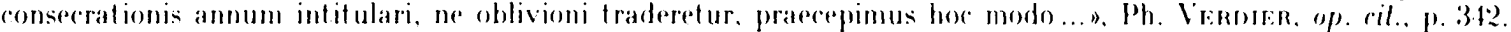

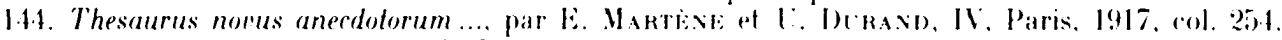

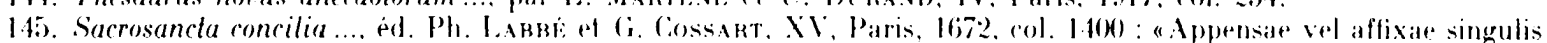
ecclesiis tabellae reliquiarum omnium nomina publice descripte proponentur" (a). $\mathrm{XI}, \S 3$ ).

146. (i. Pavazza. Lapidi e scullure ... di P'aria. n" 95. p. 27.

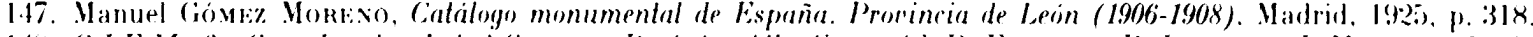

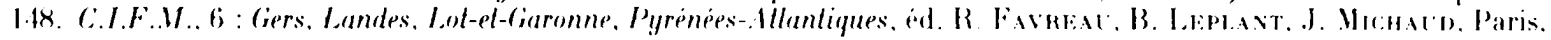
$19 \times 1$. p. $10-11$

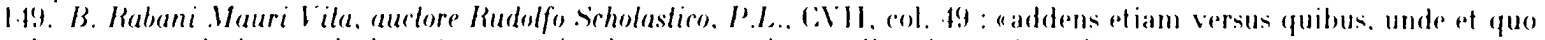
ef ad quem translati sunt declarantur, metrica lege compositos ef litteris aureis scriptosn. 


\section{IDEPOSCENS OMIVES TEMPLLM QLI GRESSIBLS IVTTRANT, IPSI W I'T COM.MENIENTT RITE DEO PRECIBLS ${ }^{150}$.}

Raban rédige encore des inscriptions métriques pour les reliques de sainte Cécile et des saints martyrs Tiburce et Valérien, des saints martyrs Janvier et Magne, de sainte Félicité et autres saints et saintes, des saints évèques Corneille, Calixte, sixte, Sinisius, Nicaise. Félix et autres prêtres, martyrs et vierges ${ }^{151}$, avec la mème intention de publicité : nomine quos locus hic et imagine nolat; horum tu, lector, si noscere nomina curas; horas nunc admoneo. La translation, en 975, à Saint-Pierre de (iand des restes de saint Florbert, abbé de Saint-Bavon, était aussi "attestée» (lestalur) par une inscription sculptée dans la pierre, en lettres grecques et latines, placée près des reliques du corps:

HIC: REQUIESCIT CORPLS FLORBERTI, DISCIPLLI ET ORDINATI AMANDI EPISCOPI, CLUS IEPOSITIO CELEBRATLR KALEVIAS NOVEMBRIS ${ }^{152}$.

On notera ici les termes de lestalur et de celebratur, qui soulignent clairement les fonctions de cette inscription qui apporte un témoignage historique, et commémore une célébration liturgique.

A Rome en 1110 le pape Pascal II fait la dédicace de Saint-Matthieu in Merulana et en consacre les quatre autels, dans lesquels il dépose des reliques. L'inscription donne le détail de la cérémonie et ajoute :

ET EGO PASCHALIS PAPA ... HAS SANCTORLM RELIQLIAS OCULIS PROPRIIS VIDI, MANIBLSQLE MEIS ATTRECTAVI ET RECONDIDI CLM ANTIQLO TITULO IN ARCA MARMOREA SLB ALTARI MAJORE, AD CUJUS CONSECRATIONIS ANNIVERSARIUM IECREVIMUS ... 153

Les historiens qui étudient le culte des saints et leurs reliques auraient grand avantage à utiliser les renseignements, datés et localisés, que fournissent les dizaines d'inscriptions de dédicaces, de consécrations d'autels, de reliquaires, conservées en chaque pays. On peut encore joindre à cette catégorie d'inscriptions celles qui identifient les figures des saints dans les églises ou qui décrivent leur vie. Elles participent, à la publicité que les églises tiennent à faire de leurs saints, qui font leur gloire et aussi souvent leur fortune. A cet égard la vie de saint Ambroise racontée sur l'autel d'or de Saint-Ambroise de Milan, celle de saint Émilien décrite sur la châsse de San Millán de la Cogolla, celle de saint Geminiano sculptée au linteau de la "porta dei principi" à la cathédrale de Modène, celle de saint lladelin ciselée sur la chàsse de Saint-Martin de Visé, celle de saint Calmin représentée sur la chàsse de Mozac, toutes accompagnées d'inscriptions, ont tout autant d'importance que les Vies ou Livres de miracles qui vantent les mérites des saints patrons. On a même, à Santa .laria in Via a Rome, en 1256, le récit, gravé dans la pierre, d'un miracle survenu en la maison du cardinal Pierre Capocci et l'attestation de reliques et de guérisons qu'elles procurent ${ }^{154}$.

Les dédicaces d'églises vont être accompagnées de l'octroi d'indulgences à partir de la seconde moitié du XI" s. Lorsque le pape Alexandre dédie la basilique de Saint-Benoît du Mont-Cassin en 1071 , il accorde la rémission de leurs péchés à ceux qui auront assisté à la cérémonie ou qui seront venus au Mont-Cassin par dévotion dans la semaine suivante ${ }^{155}$. Lrbain II accorde à son tour en

150). Ibid., (o) st. st.

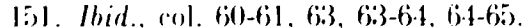

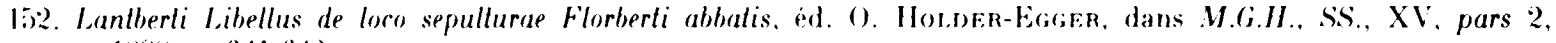
Hanovere. I888, p. 611-6.42.

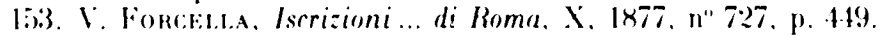

15.4. Mid.. VIII, is76, n" x15, p. 357 .

15\%. P.L.. C.XILX. col. 9.41. 
1093 une indulgence plénière à ceux qui visiteront l'église de Notre-I)ame de Benza, qu'il vient de consacrer, au jour anniversaire de la dédicace, à Pâques et aux fêtes de la Vierge ${ }^{156}$, et cette même indulgence plénière est par lui décidée pour ceux qui visiteront l'église Saint-.Nicolas d'Angers au jour anniversaire de sa consecration ${ }^{157}$, comme aux croisés qui participeront à la guerre pour la délivrance de Jérusalem ${ }^{158}$. On voit bien l'intérêt qu'il y avait à faire connaître le plus largement et le plus durablement possible ces concessions d'indulgences, et on peut, effectivement, à partir du XII" s. enrichir l'étude des indulgences grâce à l'apport des inscriptions. On les trouve décrites à Rome dans des inscriptions de Saint-Matthieu in Merulana en 1110, de Sainte-Agnès en 1123, de Sainte-Marie in Aquiro en 1179, de Saint-Nicolas de Funari en 1180, de Saint-Jean-de-la-PorteLatine en 1190, de saint-Eustache en $11966^{159}$. Elles figurent aussi dans des inscriptions de dédicace à Vogal de las Huertas en Castille en $1166^{160}$, à Santa Maria in Stelle à Vérone en $1187^{161}$, à Viterbe en $11988^{162}$, à Montpellier en $1200^{163}$. Pour le xull s. on a d'autres témoins épigraphiques à Rome ${ }^{164}$, à . Wewenham en 1235) ${ }^{165}$, à Viterbe en 1258 et $1289^{166}$, à Mayence en $1284^{167}$, à Vienne en 1290168, et celte liste, qui n'est pas exhaustive. se poursuit bien au-delà du xin" s. Ces inscriptions peuvent reproduire la totalité d'une bulle pontificale comme en l'église Sainte-Lucie della Tinta à Rome en 1278 ou à la cathédrale Saint-Laurent à Viterbe en 1289. Le plus souvent elles indiquent les indulgences accordées et les jours fixés pour en bénéficier, à partir des formules mèmes que l'on trouve dans les concessions pontificales d'indulgences. Elles sont placées très en évidence, de manière à pouvoir ètre lues par tous les fidèles qui fréquentent les églises bénéficiaires de ces indulgences.

(On peut encore trouver une fonction liturgique aux fondations de messes, d'anniversaires, de luminaire, de distributions d'aumônes, etc., qui accompagnent le plus généralement les dispositions testamentaires. Les anniversaires commencent à se multiplier au $\mathrm{xI}^{\circ} \mathrm{s} .{ }^{169}$, mais dans les inscriptions on ne les trouve guère avant le XII" s., leur nombre ne devenant important qu'à partir du XIII" s. Les inscriptions ne correspondent qu'à une publication des dispositions figurant dans les chartes qui ont d'abord èté établies de ces fondations. Une inscription de 1277 . aujourd'hui disparue, a San Ciacomo alla Longara à Rome le disait expressement. Le texte se présentait comme un rappel au clergé de l'église:

\section{MEWORIA SIT (OLLEGIO HLIIS ECCLESIAE QUOI) TENENTUR FIRMITER HOC AGERE UT CELEBRETUR IN EA SEMPER EX VUNC OMNI IIE MISSA .. ET A.VNIVEISSARIITH ETIAM ...,}

et se terminait par la mention :

\section{HAEC ALTEM CALTA SEXT INSTRL UENTO PLBLICO SCRIPTO PER VICOLALM CARBONIS NOTARIL M ${ }^{170}$.}

15). Ihid.. (:I.I. col. 365).

157. Sermon d'Hildebert de Lavardin pour la dedicace d'une église, P.L., CLXXXI. col. 751-752.

158. Ihid.. (:I.1. col. 4x:3.

159. Ces inscriptions peuvent ètre relevées dans le recueil de $\mathrm{V}$. Forcella sur les inscriptions de Rome.

160. Miguel Angel (iancia (icivea, El arle romanico en Palencia, op. cil., p. 90.

161. Saggi e memorie di storia dell'arle, 6. 1968, p. 13. n. 22.

162. A. Cанов: Le epigrafi medievali di Vilerbo..., n" 9, p. 38-40.

163.3. C.I.F...., 12: Aude, Hérault, p. 134-136.

164. Sainte-Sabine. Sainte-Bibienne, Sainte-Marie-de-la-Consolation. les Saints-Quatre-Couronnés, Saint-Adrien, Sainte-Martine, Saints-Jean-et-Paul, Saints-Marcellin-et-Pierre, Sainte-Lucje della Tinta, Saint-sauveur in Pensili.

165. Ch. Bohalit me Fifery, La Sainte Vierge. Eludes archéologiques el iconographiques, Paris, II, 1878, p. 425.

16fi. A. Carosi, op. cill., n" 15, p. 52-53; n" 32, p. 92-95.

167. Die Inschriften der Stadt Mainz on frühmittelalterlicher Zeit bis 16.50, op. cil.. n"2:3. p. 29.

16). A saint-Andre-le-Bas: A. DE Trerrebasse, Inscriptions antiques el du moyen agge de lienne en Dauphiné, II.

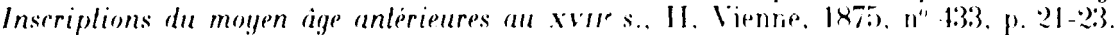

169. Auguste Moloxiser, Les obituaires au moyen age, Paris. 1690, p. 105-138.

170. V. Foncelta. Iscrizioni ... di Roma. VI, 1875, n" 1061. p. 32.4. 
De même une fondation de luminaire à San Lorenzo ai Monti à Rome en 1290 renvoie à un instrumento prius scriplo per Jacobum Thome notarium ${ }^{171}$. Les clercs qui doivent assurer ces pieuses dispositions ont donc les documents originaux dans leurs chartriers. Encore faut-il aussi que la mémoire de ces dispositions ne soit pas perdue, que tous les fidèles en soient informés, afin qu'ils puissent s'y unir et prier pour les donateurs, sans doute également afin qu'ils soient encouragés à faire de semblables fondations, d'où cette notification, de forme diplomatique, qui introduit certaines de ces inscriptions. Ainsi a Saint-Ignace de Vayence au milieu du XII" s., pour une fondation danniversaire par un couple : Yolum sil omnibus lam presentibus quam futuris quod ego Helfricus el uxor mea Christina ... ${ }^{172}$, ou encore, à Notre-I)ame de Vanxains, au début du xul" s.. pour une inscription placée immédiatement derrière le maitre-autel : Sciant lam presentes quam posteri quod ... ${ }^{173}$. A schönau, au XIII" s., une inscription rappelle, sur un mode impersonnel, que gràce à la largesse des fidèles tous les autels de l'abbatiale doivent ètre pourvus de cierges qui brùleront pendant les messes. et que. en temps dhiver, deux lumières seront fixées à un candélabre a l'autel de la Vierge, et ne seront jamais éteintes ${ }^{174}$. A Eltviele, en 1095 , notification est faite à tous dans une grande inscription de plus de deux mètres de large - hic cunctis legentibus pateal qualiter ... - que Reginbraht et Irmingart sa femme ont donné à l'église du lieu une vigne, un champ, deux prés, avec obligation de chanter une messe quotidienne, de faire l'aumòne à vingt pauvres le jour de la Toussaint, et de fournir l'église de soixante cierges. Elle se termine en mentionnant que c'est avec le congé de l'archevêque de Mayence que ce texte a été inscrit dans la pierre ${ }^{175}$. I a aussi, dans ces inscriptions relatives à la liturgie, on retrouve ces deux notions fondamentales de l'épigraphie, la publicité et la durée.

Les inscriptions ont encore pour fonction d'expliquer le programme iconographique. Les Libri carolini mettent bien en lumière cette raison d'ètre des inscriptions. Lorsque, disent-ils, on voit deux belles figures de femme, on ne peut distinguer s'il s'agit de la Vierge ou de Vénus. Le peintre lui-même ne le sait pas. Invité à s'expliquer, il ajoute soit le nom de Vénus, soit le nom de la Mère de Iieu, et désormais on vénerera la seconde, on rejettera la première ${ }^{176}$. De mème, si l'on voit peinte une belle femme tenant un enfant dans ses bras, on ne pourra savoir s'il s'agit de Marie tenant Jésus enfant, ou de Sara avec Isaac, Rébecca avec Jacob, Bethsabée avec Salomon, Elisabeth avec Jean, ou encore mème lénus avec linée, Alcmène avec Hercule, Andromaque avec Astyanax, a moins qu'une inscription neeclaire le spectateur ${ }^{177}$. Après avoir fait peindre dans une eglise, autour d'un autel, les images de saint Boniface et de ses compagnons, Raban Maur ajoute : "Si tu cherches, lecteur, a connaitre leurs noms, regarde la peinture et lis les inscriptions" 178 .

Les identifications des personnages ou des scènes sont la forme la plus simple de ce type d'inscriptions. Elles se font par le nom ou, pour les personnages bibliques, soit par leur nom, soit par une citation de leurs écrits, et, dans le cas des évangélistes, parfois par les premiers mots de leur évangile. sur la frise de . Notre-I)ame-la-(irande a Poitiers, Eve et le roi Cabuchodonosor sont accompagnés de leur nom. les quatre personnages suivants. I)aniel. Jérémie. Isaïe, Moïse, sont distingués par un texte de leurs ceures inserit sur une banderole ${ }^{179}$. Au baptistère Saint-Jean de

171. Mid.. I. 1874, n" 436i, p. 151.

172. Lie Inschriften der stadl Mainz.... op. cil. n" 17. 1. 2:3-2:)

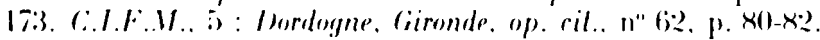

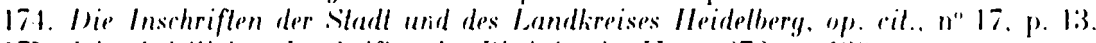

17). Die christlichen Inschriften der Rheinlande. II. n"27.2, p. 1:301

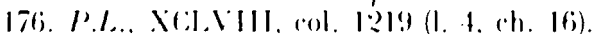

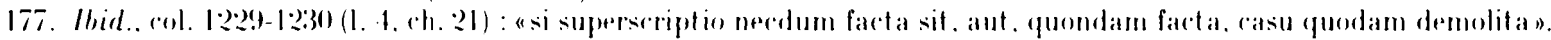

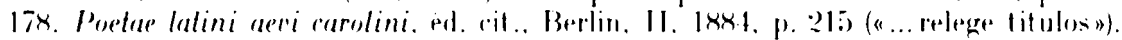

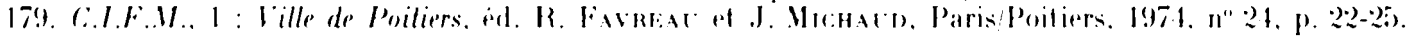


cette même ville. la scène où Salomé reçoit des mains du bourreau la tête de Jean-Baptiste est identifiée par les simples mots puella et capud ${ }^{180}$. Très souvent ces identifications des représentations sont introduites par hic, ecce, ubi, ce qui en souligne le caractère pédagogique : $H i$ sunt elephantes, "ce sont des éléphants", à Aulnay, Hic est diabolus, "voici le diable" à Saint-Pierre de Chauvigny, Lbi Ianiel missus est in lacum leonum, "où Daniel est jeté dans la fosse des lions", à San Pedro de la Nave.

Si ces inscriptions qui identifient sont précieuses, combien plus intéressantes sont pour l'épigraphiste et l'historien de l'art celles qui commentent, expliquent, font connaitre le sens que l'auteur du programme a retenu. Dans un de ses poèmes Raban Maur a souligné que la peinture était plus agreable que l'écriture, mais qu'elle était plus superficielle et pouvait ètre trompeuse. alors que l'écriture sert mieux le sens et le vrai et qu'elle est "la norme parfaite du salut "181. Guillaume Durand semble reprendre le même discours lorsqu'il dit que «la peinture émeut plus l'àme que l'écriture, mais que l'écriture est plus apte à garder la mémoire des faits» ${ }^{182}$. Le chroniqueur bourguignon qui nous décrit l'œuvre de l'abbé Guillaume de Volpiano à SaintBénigne de Dijon a bien marqué l'importance des inscriptions pour expliquer le sens profond de l'œuvre : "Ce n'est pas en vain que la beauté et la subtilité de l'œuvre d'art sont montrées par des lettres à ceux qui sont moins instruits, parce que beaucoup d'aspects en elle ont un sens mystique, qui doivent ètre plus attribués à l'inspiration divine qu'à l'habileté d'un maitre, quel qu'il soit "183. Un siècle plus tard l'abbé Suger à Saint-Denis écrit de même: "Comme la diversité des matériaux. or, pierres, perles, ne facilite pas à la perception muette des yeux l'apprehension de sujets dont le sens n'est clair qu'aux savants, je fis expliquer par des inscriptions en relief ces allégories brillantes, d'un sens si excitant pour l'esprit. Voici les vers que je fis inscrire pour en extraire la moelle» ${ }^{184}$.

La fonction pédagogique est fortement soulignée dans ces inscriptions qui donnent le sens. Sur une cuvette décorée de scènes de la vie de saint Thomas, une inscription invite les lidèles qui veulent connaître les mérites du saint à examiner avec soin ce qu'ils ont sous les yeux : ... si scire fideles haec perscrutentur quae coram sculpta videntur ${ }^{185}$, et au tympan de la cathedrale de Jaca. l'inscription, avant de donner le sens, avertit qu'elle s'adresse au lecteur qui aura le souci de comprendre ce qui est représenté dans le programme sculpté : Hac in sculplura lector sig noscere cura ${ }^{186}$. De même sur la couronne de lumière de l'ancienne abbatiale de Saint-Nicolas à Grosscomburg, vers 1139, il est demandé à chacun de chercher ce que l'œuvre figure pour lui, Querere mens curet quid opus sibi lale figurel, la très longue inscription fournissant par la suite les explications de ce qui est représenté : le cercle signifie de façon mystique (mysticat) la structure de l'Église, les douze tours représentent (monstranl) les apôtres, l'éclat du métal est la figure (signal) de la foi, la chaine est l'image (designatur) de l'espérance ${ }^{187}$. L'introduction du sens est donnée par des verbes explicites, signare, designare, docere. I)ans la bible de Floreffe une inscription au début de l'évangile de Luc explique une peinture de la Crucifixion en indiquant que le taureau, symbole de Luc, est l'animal du sacrifice, et que le Christ est le taureau :

180. Ibid.. n" 15. p. 14-15.

181. P.L.. (CXII (Carmen ad Bonosum): - Poetae latini aevi carolini, edd. rit.. p. 196.

182. (iuillaume DCRavo, Rationale divinorum officiorum. I. 1. ch. De picturis : "per scripturam res gesta quasi per auditum qui minus movet animum ad memoriam revocatur".

183. V. Montet. Recueil des textes relatifs a l'histoire de l'architecture el at la condition des architectes en France an moyen age. Paris, I. 1911, n" 6. p. 27 (Collection de textes pour servir a l'etude et i l'enseignement de l'histoire. 14).

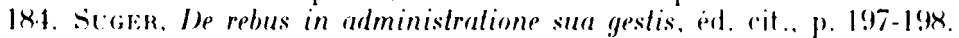

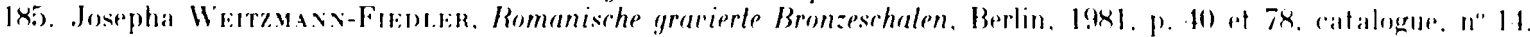

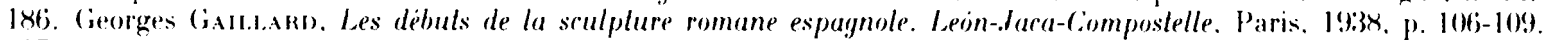

187. Anton Leaver. Deutsche Kunst der Romanik. Munich. 1982. p. 107 et 192-19:3. fig. 1.49. 


\section{PRO VEIO FRAIIDS VITLLLS IATLR HOSTIA LALIIS QIOI CIRISTI S IITILISS SIT DOCET HIC TITILISS188.}

Dans l'évangéliaire de Strahow, de la fin du $\mathrm{x}^{\prime}$ s., les inscriptions qui accompagnent les portraits des évangélistes font de mème le rapprochement entre eux ef leurs symboles en utilisant le verbe designare ${ }^{189}$, tandis que dans le Codex Aureus d'Echternach les inscriptions qui donnent la mème explication emploient le verbe signare ${ }^{190}$. A la façade de la petite église saintongeaise de Pontl'Abbé-d'Arnoult, à la fin du $\mathrm{xr}^{\prime}$ s., est figuré un agneau, dont une inscription donne le sens :

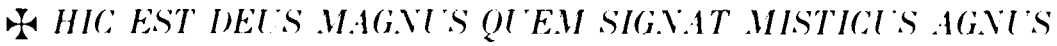 \\ C"est le Ijéu grand que désigne l'Agneau mỵtique 191.}

Au début du xir"s. le chandelier de bronze qui aurait eté fondu a Gloucester et donné à la cathédrale du Mans est décoré de monstres et de Vices, mais il est porteur de lumiere, et une inscription métrique explique que cette lumière enseigne (predicat) que l'homme n'est pas plongé dans les ténèbres du vice ${ }^{192}$. La longue inscription de la couronne de lumière d'Aix-la-Chapelle, vers $1165 / 70$, commence par un vers qui donne le sens général : "C'est la Jérusalem céleste qui est signifiee (signalur) par cette image "193. Le Christ en . lajesté peint en l'abbatiale de Kinechsteden est aussi le Sauveur du monde, comme l'indique l'inscription :

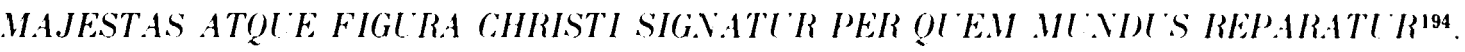

On pourrait multiplier les exemples de ces textes épigraphiques qui fournissent le sens de l'image. Certains ensembles sont entièrement bâtis sur des explications typologiques ou allégoriques de l'Écriture. Le retable de Klosterneubourg est un exemple présent à tous les esprits. Sur le tableau, réemployé pour servir de reliure, du musée Condé à Chantilly, les préfigurations bibliques de la Crucifixion sont accompagnées d'inscriptions pour guider celui qui regarde cette (xuvre foisonnante : ainsi le sacrifice d'Abel désigne (nolal) le Christ sur la croix, dans le sacrifice d'Abraham le bélier préfigure (prefert) ce qu'apporte l'Homme-I)ieu devenu victime, Isaac portant le bois du bûcher annonce le Christ portant sa croix (sir crucis es Christus ... portitor), il faut voir (aspice) dans le serpent d'airain le type (typicum) de celui qui rachète les peuples, les deux bois de la veuve de Sarepta sont les "signes mystiques" de la croix, ete. ${ }^{195}$. Ies inseriptions jointes par l'abbé suger aux vitraux de saint-Ienis constituent un des meilleurs exemples qui soient de ces textes qui commentent les images, à l'instar de ces nombreux commentaires de l'Écriture qui nous ont été conservés de Tertullien à Adam de Saint-Victor. Que lire dans la scène où un homme fait tourner la meule tandis qu'on lui apporte des sacs de grains, si l'on n'a pas sous les yeux le commentaire épigraphique : "En tournant la meule pour séparer, Paul. la farine du son, lu nous expliques (nota facis) le sens caché de la loi mosaiquen. La ou un voile est enlevé du

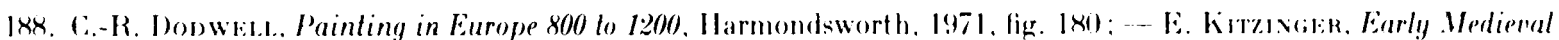
Irt in the Brilish .1/useum. Londres. 1955), p. 112. fig. 13 (Londres. British Library. Add. Ms. 177:3x, fol. 187). ()n troute

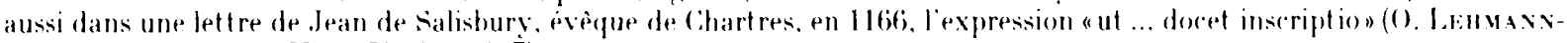
Brockhals, op. cit., II. n"

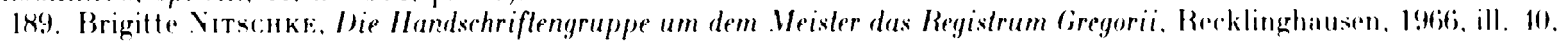
4.2 .

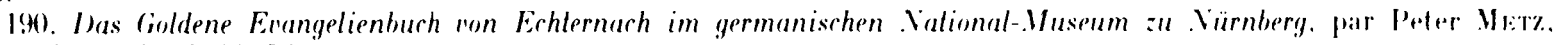
Munich. 19:56, pl. :3:3, 5:3.

191. C.I.F.M. 3: Charente, Charente-Marilime, Meus-tères, op. cil. p. 1001.

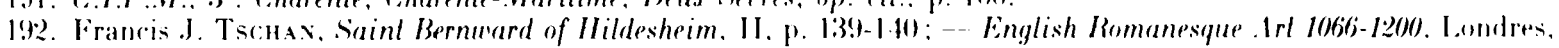
$19 \times 4,110247,0.294$.

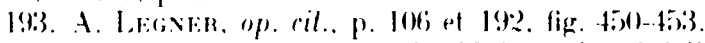

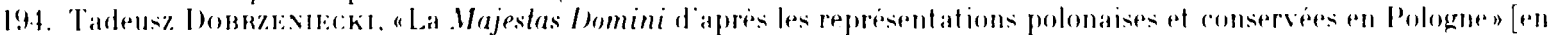

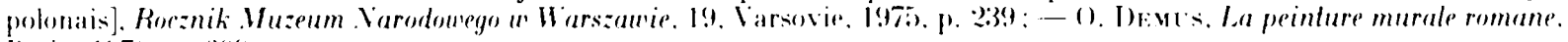
Paris, 1970), 1. 6019.9.

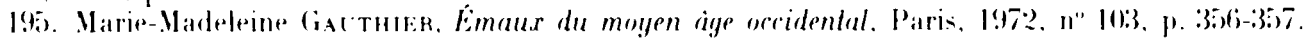


visage de Moïse on comprendra que ce qui est voilé chez Moïse est révélé par la doctrine du Christ :

\section{(UOD MOYSES VELAT, CHRISTI DOCTRINA REVELAT.}

Là où on voit le buisson ardent, on se réfèrera au Christ empli d'un feu divin, et dans le serpent d'airain il faut voir le Christ en croix (sicul..., sic...) ${ }^{196}$. Les vitraux de la cathédrale de Cantorbéry, vers $1175 / 80$, sont bâtis selon le même accompagnement de l'image par le texte. Isaac qui porte le bois du bùcher est le type de la croix (crucis typum manifestal), les deux morceaux de bois de la veuve de Sarepta sont en signe de la croix (crucis in signum), le serpent d'airain est une figure de I)ieu en croix (sic Deus in ligno), la mort d'Abel annonce (signet) la mort du Christ, le tau inscrit avec le sang de l'agneau est la figure du crucifié (precinuil), Samson dormant est le type (lypice) de l'ensevelissement du Christ, David qui délivre la brebis, c'est le Christ immolé pour son troupeau (sic Chrislum significavit), comme Jonas est resté trois jours dans le ventre de la baleine, de mème (sic Deus) Dieu est resté trois jours au tombeau, comme Jonas a été rejeté par la baleine, ainsi (sic) Jésus est ressuscité, Joseph qui sort de la citerne, c'est aussi le Christ qui ressuscite (le signal, Christe, Joseph), "l'enfant Samuel signifie le Christ, l'amphore le vin, la triple offrande signifie la forme trinitaire de celui qui est double de nature" ${ }^{197}$.

Comme l'avait fait inscrire Suger à Saint-Denis, sur l'antependium de l'autel des corps saints, "le signifié plaît davantage que le signifiant" ${ }^{198}$. Il faut, selon son propos même exprimé dans le passage oú il traite des vitraux de son abbatiale, s'éveiller au spirituel à partir du matériel, de materialibus ad immaterialia. C'est un thème qui apparait plusieurs fois dans les inscriptions. Dans la porte de la cathédrale de Troia il faut voir non seulement l'entrée matérielle, mais l'entrée spirituelle qui est offerte au fidèle :

\section{ISTILS AECCLESIAE PER PORTAM MATERIALIS \\ INTROITUS NOBIS TRIBLATLR SPIRITUALIS.}

La remise des clés à Pierre au tympan de l'ancienne église Saint-Sauveur de Nevers doit ètre comprise de façon symbolique :

\section{VISIBLS HLMAVIS MONSTRATUR MISTICA CLAVIS'199.}

Ce qui se passe sur l'autel matériel doit trouver son accomplissement dans l'autel spirituel du cœur, comme on le trouve gravé sur des autels portatifs de Cologne, Siegburg, Xanten:

\section{OLICOLID IN ALTARI TRACTATLR MATERIALI CORDIS IN ALTARI COMPLETLR SPIRITLALI200.}

Le calice d'argent de Wilten a une inscription de même type :

\section{A HIC QIOICLMQLE VIDES RES SIGNAT SPIRITLALES ${ }^{201}$.}

Dès lors, il s'agit de bien comprendre ce qui est représentè. Sur le devant d'autel en stuc, polychromé, de Saint-Marcel de Planès en Catalogne, le Christ est peint en Majesté, avec, sur le

196. SugFr. Ie rebus in administratione sua gestis. èd. cit., p. 204-206; - Louis (GRonfcki, "Les vitraux allégoriques de Saint-I)enis", Art de France, Paris, I, 1961, p. 19 et ss, et surtout Les vitraux de Saint-Denis. Etude sur le vitrail au XIr s., Paris, 1976 (Corpus vitrearum medii aevi).

197. X. Barhifr dF Montallt, Traité d'iconographie chrétienne, Paris, 1898, II, p. 45-47; -- English Romanesque Art 1066-1200, n" 91, p. 1.11.

198. Ph. Verder, "Siant-Denis ef la tradition carolingienne des tituli ...", p. 345-3446 : "Significata magis significante placent".

199. Jean It:powt, Nivernais-Bourbonnais roman. La Pierre-qui-Vire. 1976. p. 37 at pl. 5.

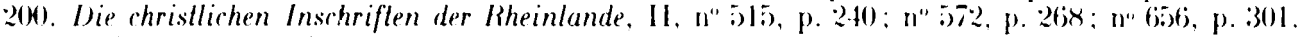

201. A. Legivir, op. cil., p. 8.3 et 186, fig. 366. 
livre, la citation : Ego sum Lux mundi (Jean VIII, 12). La leçon semble claire en elle-mème. Encore ne faut-il pas s'attacher à une simple peinture, car "Dieu est perpétuelle majesté et pouvoir suprême, qui n'est enfermé par nulle peinture ou figure", selon l'inscription qui a été ajoutée autour de la mandorle:

\section{VILLA PICTTRA CONCLISA SIIE FIGLRA PERPES MAJESTAS DEIS EST ET ST MMA POTESTAS202.}

Le mème souci de ne pas tomber dans un culte idolàtrique a conduit à une belle formule, due à Baudri de Bourgueil, gravée au tympan de San Miguel d'Estella, sur un retable et une monstrance de l'abbatiale de Saint-Denis, au tympan de la Porta dei Hesi à la cathédrale de Ferrare, sur un reliquaire du musée de l'Ermit age à Leningrad, et. sous une forme proche, sur un ivoire du Museo nazionale a florence :

\section{VEC IELS EST VEC HO.MO PRAESENS OLAM CERNIS IMAGO SEI) IELS EST ET HO.MO PRAESE.SS OI'E.M SIGNAT IMAGO203.}

Herrade de Landsberg dans son Hortus deliciarum a repris le mème texte ${ }^{204}$, et Guillaume Durand le donne en modèle dans son Rationale divinorum officiorum ${ }^{205}$. On peut encore citer un texte très proche sur une mosaïque de Saint-Marc à Venise ${ }^{206}$. Dans ces différents exemples, qui comportent quelques variantes, on notera, a còté de la formulation théologique, l'insistance pédagogique à expliquer l'image - imago est répété quatorze fois - par les verbes figural (5 fois), signal (4 fois), cernis (4 fois), docel (1 fois).

On pourrait multiplier les exemples d'inscriptions qui se présentent comme un commentaire de l'image. La contrainte de place souvent imposée à l'épigraphiste, a conduit à la trouvaille de formulations bien frappées. Pour rappeler le mystère de l'Incarnation on trouve, en accompagnement d'une Vierge à l'Enfant:

\section{IN GIREMIO MATRIS RESIDET SAIPIENTIA PATRIS}

à Arezzo, Beaucaire, Eichstätt, Prague, Saint-Junien ${ }^{207}$,

\section{VIRGO) CREATOREM GENTIT GEVITRIX GEVITOREM}

sur la chàsse reliquaire de saint Roman à Reiningen ${ }^{208}$,

\section{INGENTT M VATIM GREMIO FERT VIRGO LOCATLM}

sur un vitrail de 1 issembourg ${ }^{209}$. De nombreuses inscriptions, sur les patènes et les calices en particulier. se rapportent à l'eucharistie. Sur la patène dite de saint Bernward d'Hildesheim

21):. Lart roman. Eirposition organisee par le goupernement espagnol sous les auspires du Conseil de l'Europe. Catalogue. Barcelone (ompostelle. 1961, p. 1.11 (antependium conserve aux Wuseos de arte de Barcelone).

20:3. R. Favreal. "L inscription du tympan nord de san Miguel d'Estella". Bibl. Ese des Chartes. CXXXIII. 1975), p. 237-2.16: pour le reliquaire de Leningrad. voir E. A. Lapkovskaya, L'arl applique du .Moyen Áge au Musée de l'Ermilage. TEurres en métal, Mosecou. 1971. n" - $8-9$.

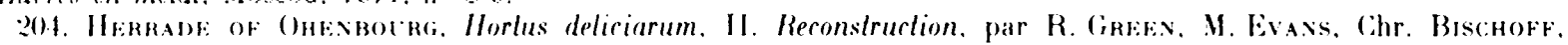

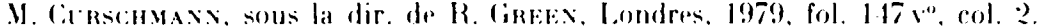

2(1). Livre I, rubrique De pirluris el corlinis el ornamentis erclesiae.

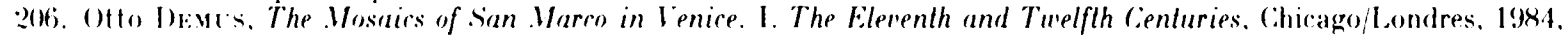
p. ¿xi.

207. R. Favreal of J. Vichard, "Les inseriptions du tombeau de Saint-Junien", dans Acles du 102e congres national des

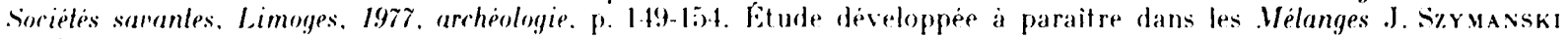
(R.F.).

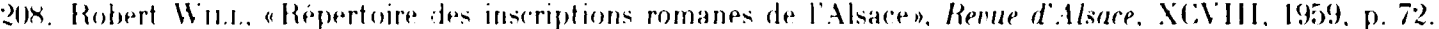

209. Rüdiger Beckswavi. " Das Jesse-Fenster aus dem spätromanischen Chor der freiburger Münsters. Fin Beitrag zur Kunst um 12(4)". Zeitschr. deutschen ler. f. Kunsturiss. X.XIII. 1-4. 1969. p. 45. fig. 31. Lexpression ingenitum natum reperend le symbole de Nicese genilum non factum. 
conservée au musée de Cleveland, le Christ tròne en Majesté, entre le tétramorphe el les quatre vertus cardinales identifiées par leur nom. Autour est inscrit:

\section{HIC: SPECTATE VIRI : SIC VOS MORIE.VIOO REDE.HI.}

et sur le bord de la patene, on lit:

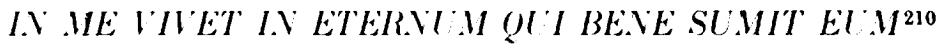

qui rappelle le texte de Paul (I Cor., XV, 16). avec des mots ou expressions empruntés à la Bible (nivat in eternum, frangere, sumere). Sur la patene de Fritzlar est grave :

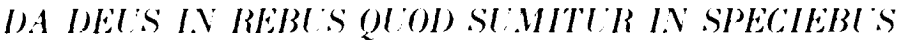 CONSTAT IN ALTARI CARIE.M IDE PANE CREARI}

affirmation de la présence réelle qui prend une dimension supplémentaire quand on sait que Bérenger de Tours aurait prononce le second vers lorsqu'il avait rétracté sa doctrine mettant en doute la "transsubstantiation" ${ }^{212}$. La rédemption par la croix déja évoquée sur la patene de Cleveland, est ainsi exprimée dans le retable de Klosterneuburg :

\section{VICTIMA MACTATR QI'A WOSTRA RI TIA LEVATTR ${ }^{213}$.}

Le Christ ressuscité, par qui la mort est vaincue, est présenté sur le tympan de San Andrés d'Armentia par un agneau et la riche formule:

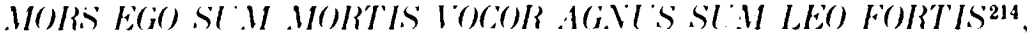

ou l'on évoque et Isaïe (IIII, 7) of Osée (XIII, 14) et la figure du lion, symbole de la Résurrection au dire des bestiaires, ou encore, au-dessus du crucifie de la croix de la reine (isisèle :

\section{ECCE SALIS ITTE PER OIAL WORS VORTIA WORTE215.}

En ce domaine un texte très court, comme l'est généralement une inscription, peut mener loin dans les commentaires exégetiques ef theologiques.

Ces inscriptions peuvent aussi expliquer, commenter un programme qui ne soit pas religieux. mais celles qui nous sont conservées en ce domaine ne sont qu'un petit nombre. Notons seulement à titre d'exemple les premiers mots des Instilutes de Justinien qui proclament la fonction judiciaire du palais des vicomtes de Saint-Antonin ${ }^{216}$.

Dans la Psychomachie Prudence, s"inspirant de l'Apocalypse ${ }^{21 i}$ décrit le nouveau temple. Dans le vestibule, "icrits (inscripta) en or au-dessus des portes brillent les douze noms du sénat

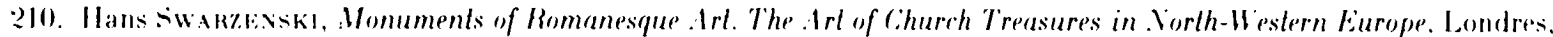

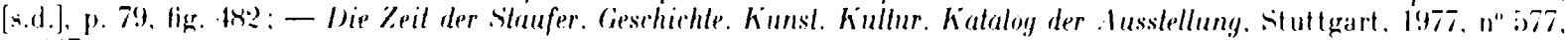
p. 4.17 .

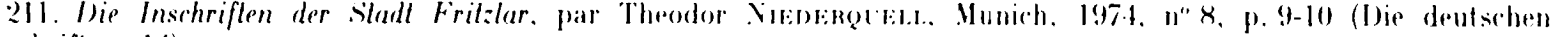
Inschriften. 1.4)

212. Anonyme de Melk. De seriploribus ecclesiasticis, P.L. CXXIII col 979.

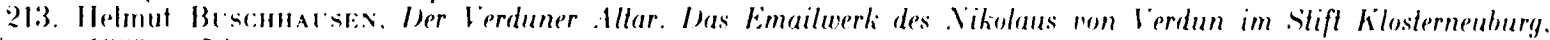
Viemme. I980), p. 5is.

211. Phototheque du Centre dEtudes Superientes de Civilisation Medievale (Poitiers).

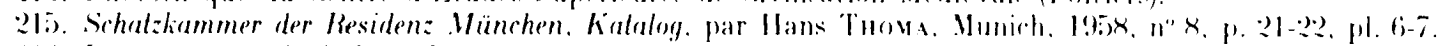

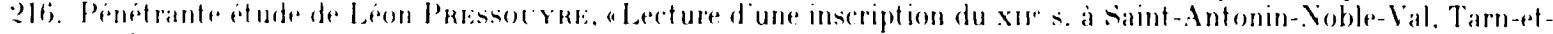

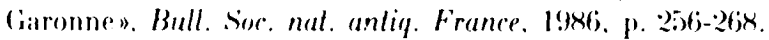

?17. Apor.. XXI. 1:-11. 
apostolique. Par cette ceinture d'inscriptions (titulis) l'Esprit sollicite les pensées secrètes de làme, appelle dans le cour les beaux sentiments»"218. C"est encore une des fonctions des inscriptions d'adresser aux fidèles des exhortations morales. Elles sont alors le plus généralement placées à la façade de l’église. au tỵmpan, sur le linteau, près de la porte, là où elles pourront ètre vues par le plus grand nombre.

Ces inscriptions sont une adresse directe aux fidèles, un peu à la manière d'une prédication. A l'une des entrées du baptistère du Latran à Rome, on lisait cette invite, sans doute du temps du pape Hilaire (461-168) :

\section{AI) FONTEV IITE HOC ADITI PROPERATE LAVANDI ${ }^{219}$.}

Cette même invilation à se hàter se lisait à la porte droite de la basilique saint-Paul-hors-lesMurs :

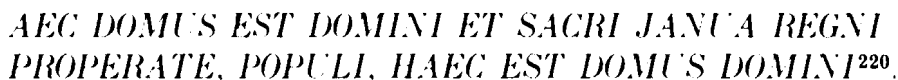

Le peuple fidèle était aussi convié à tourner ses pas vers l'église, sur le tympan de la cathédrale saint-Patrocle à Soest :

\section{+ HIC AGE, VERTE PEISEM PLEBSQIE O FIDELIS AII EIDEM ${ }^{221}$.}

La première leçon de ces exhortations morales, cest que le Christ est la porte de vie, par laquelle tous les fidèles sont invités à entrer. Ces textes sont nombreux, répétés, à quelques variantes près. selon des modèles largement répandus. Ainsi, pour prendre des exemples à travers toute la chrétienté, de cette inscription du portail de S. Giorgio in Palazzo a Milan :

\section{JANIA ST M FITAE, PRECOR, OMNES INTROVENTE

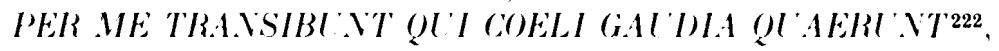

dont on retrouve le premier vers, sous une forme proche, aussi bien au tympan de Jaxa, conserve au musée de Breslau,

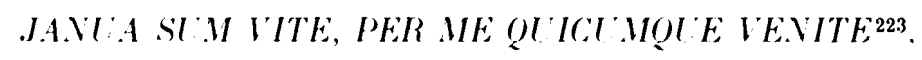

qu'au linteau du tympan de san Pablo del Campo à Barcelone :

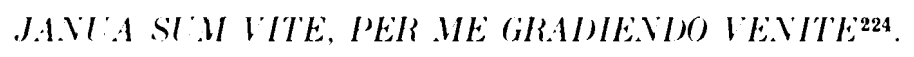

La paix est aussi souhaitée à tout fidèle qui entre dans l'église:

SIT PAX INTRANTI SIT GRACIA DIGNA PRECANTI,

a Villamartín de sotoscueva en Castille en $1175^{225}$,

SIT PAX IXTRANTI SIT GRATIA INEI PRECANTI.

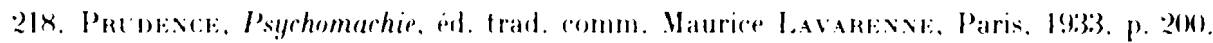

219. J.-B. DE: Rosst. Inscriptiones chrislianae urbis Romae septimo saerulo antiquiores. Rome. II. 18x8. 11. 117:- Le

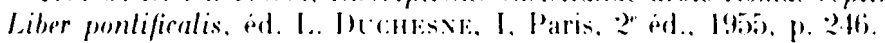

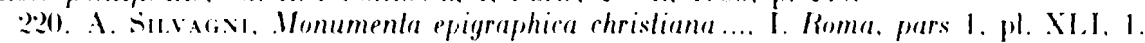

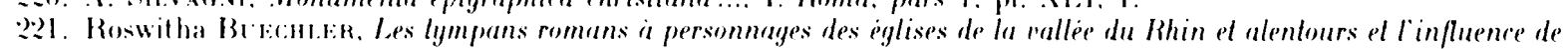

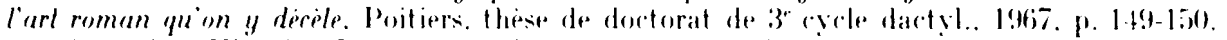

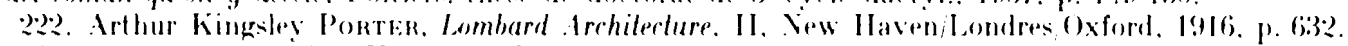

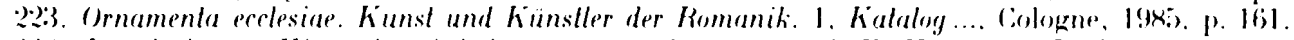

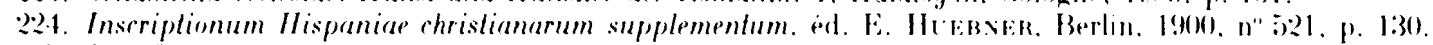

2.5. Iose Perez. Carmosa. Arguiterlura y escullura romanicas en la prorincia de Burgos. Burgos. 1959. p. 10-11. 
à la porte de Saint-Pontien à spolète au XII"s.,

$$
\text { SIT PAX INTRANTI GRATIA SIT IMGNA PREC:ATTI }
$$

à l'église de Cingoli en 1214226.

\section{PAX HIC INTRANTI SLVT PROSPERA CLNCTA PRECANTI.}

à la cathédrale de Roda en Aragon en $1225^{227}$. D'autres inscriptions présentent un souhait de paix à ceux qui entrent et à ceux qui sortent de l'église.

Cette porte de l'église est done symboliquement la porte du ciel, ouverte à tout fidele, comme il est exprimé sur plusieurs tympans de Navarre et d'Aragon, porta ... pervia cuique fideli ${ }^{228}$. Pour répondre à cet appel, il faut s'en montrer digne:

\section{A SINT PROCLL INDIGNI AL WE TRANSITE BENIG.N O.MVES TRAVSITE CI PIENTES GATIA TITAE.}

comme il est écrit au-dessus de la porte de l'église saint-.Martin à Vierstein ${ }^{229}$. Fin consépuence on trouve toute une série d'inscriptions qui appellent le fidele à la pénitence. Celle qui est gravé autour du chrisme de tympan de l'ancienne abbatiale santa llaria de las Sorores a Santa Cruz de la Seros fait bien le lien entre ces deux séries dinscriptions : "Je suis la porte perpétuelle. par moi passez, fidèles. Je suis la source de la vie, ayez soif de moi plus que de vin vous tous qui penetrez dans ce saint temple de la Vierge. Corrige-toi afin de powvoir invoquer le Christ "230. lappel à se corriger - Corrige te primum - est emprunte a Bede 231 ef se retrouve à Santh-kemy-deProvence ${ }^{232}$. Sur un marbre encastré dans le tympan de la porte nord de l'ancienne eglise priorale Notre-Dame de Cassan à Roujan, en Languedoce, se lit rette humble prière: "Qui que lu sois. homme chargé du fardeau diun detestable péché. tu nentremas pas autrement quen te prosternant sur ce seuil devant le Souverain Seigneur, car le Christ est la porte" ${ }^{233}$, ef au linteau de l'ancienne cathedrale de Vaguelonne, toujours du xu"s., Bernard de Treviers avail lait graver, en quatre vers : Au havre de vie, vous qui avez soif, venez. En passant ces portes. amendez vos mours. En entrant ici, prie et pleure sans fin tes péchés. Quel que soit le péché, une fontaine de? tes larmes le lave» ${ }^{234}$. Pour prier, il faut être en paix aver son prochain : "Lorsque vous venez pour adorer, si vous avez quelque grief contre quelqu un pardonnez jusqu a soixante-dix fois sept fois", recommande une inscription de Saint-André-le-Bas à Vienne ${ }^{235}$. Pour communier il faut aussi avoir des sentiments de pénitence : au-dessus d'un bas-relief de la lene ef du lavement des pieds, au tympan de l’église de Vandeins est écrit : "Lorsque le pécheur sapproche de la lable du Seigneur, il importe quil renonce de tout cour au péchén ${ }^{236}$. Ne pas se corriger de ses fautes. cest risquer son salut eternel, comme on peut le lire encore au linteau du lympan de la cathedrale de

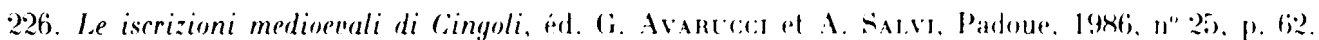

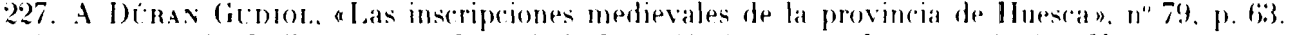

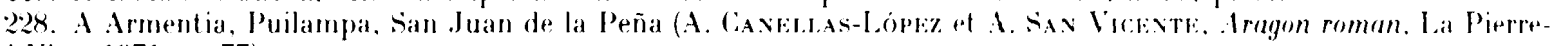
qui-lire. 1971, p. 77).

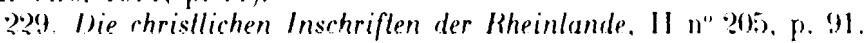

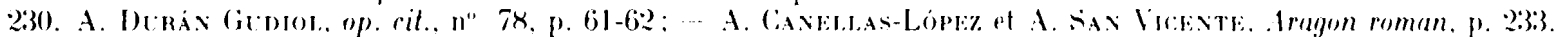

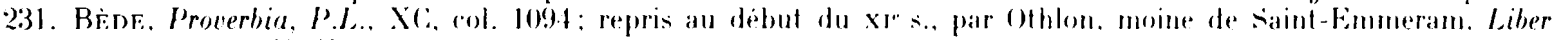
proverbiorum. P.L.. (.XIIVI. (ol. :306.

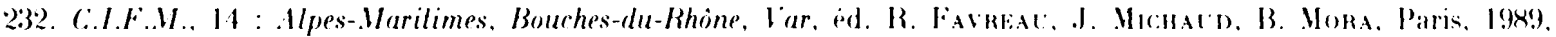
p. 126 .

233. C.I.F.M.. 12: Aude, Herault, op. cit., p. 15\%

234. Ibid.. p. $|8|$.

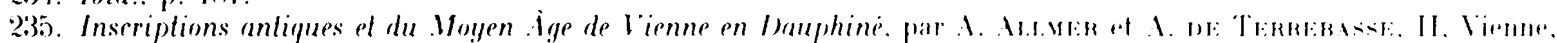

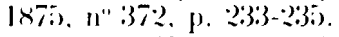

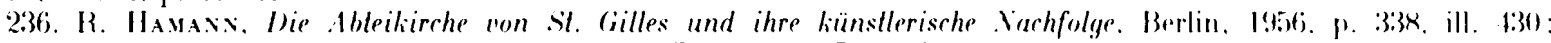

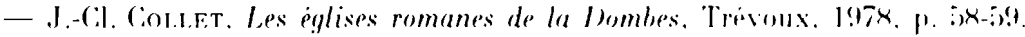


Jaca : "Si tu veux vivre, toi qui es astreint à la loi de la mort, viens ici en suppliant, renonçant aux nourritures empoisonnées. Purifie ton cceur de ses vices, pour ne pas mourir d'une seconde mort. 237 .

Lappel à la pénitence conduit donc à une mise en question face au Jugement dernier, et prend la forme d'une sévère mise en garde :

\section{O PECCATORES, TRANSMLTETIS NISI MORES \\ J DICIV U DLRIU VOBIS SCITOTE FLTLRLM. \\ O pécheurs, à moins que vous ne réformiez vos mours, sachez qu un jugement redoutable vous attend.}

lisait le pèlerin au linteau de la porte de l'abbatiale de Conques ${ }^{238}$. La mème leçon est exprimée, mais sous la forme d'une prédication sans nuance: aux bons le paradis, aux méchants la damnation :

\section{PENAS REDIDO MALIS, PREMIA DONO BONIS,}

dit l'inscription du tympan de la petite église d'Autry-Issards ${ }^{239}$, formule que développe sous une forme solennelle l'inscription du tympan de la cathédrale d'Autun : à celui qui n’a pas mené une vie impie sont promises la résurrection et la lumière sans fin, car le Christ seul dispose de tout et couronne ceux qui le méritent -- Omnia dispono solus merilosque corono. A celui qui s'est mal conduit est réservé le destin affreux dont il a, au tympan, l'image sous les yeux, la peine frappe impitoyablement ceux qu'entraîne le crime - Quos scelus exercel, me Judice, pena coercet ${ }^{240}$.

La leçon morale prodiguée par tous ces textes est donc de recourir au Christ et de se bien conduire. On trouve aussi quelques invites à s'adresser aux saints. La Vierge vient naturellement au premier rang:

\section{HEREIES VITE DOMINAM LAUDARE VENITE ...}

"héritiers de la vie, venez louer la Dame par qui est donnée la Vie, par elle le monde est restauré», peut-on lire au tympan de l'église Notre-Dame de Corneilla-de-Conflent en Roussillon, texte qui était aussi inscrit sur l'église de la Mort de la Vierge à Jérusalem ${ }^{241}$. Au tympan de l'église SainteCécile à Cologne, c'est à l'imitation des vertus de Cécile qu'est convié le fidèle :

\section{VOS QUI SPECTATIS HEC PREMIA VIRGINITATIS}

EXPECTATE PARI PARITER VIRTUTE BEARI

Vous qui regardez cette récompense qu'obtient la virginité.

Veillez à ètre gratifiés semblablement d'une égale vertü ${ }^{242}$.

Les inscriptions occupent une place particulière dans les sources historiques, elles correspondent à des besoins que ne peuvent prendre en compte ni l'image seule, ni l'écrit de la charte ou de la chronique.

La condition de l'homme est telle qu il éprouve le besoin profond de ne pas disparaitre totalement avec la mort. Il se survivra par ses enfants, par ses auvres. L'inscription sur sa tombe va, en

2:37. A. Deran (ivmol., op. rit., n" 69, p. 56.

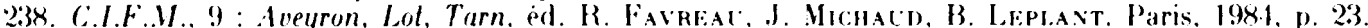

239. Jean Depoxt Nivernais-Bourbonnais romans. La Pierre-qui-Vire, 1976. p. 282. pl. 127.

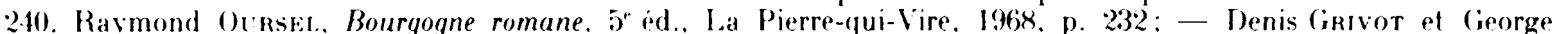
Zarviscki, Gisleberlus sculpleur d'Aulun. Paris. 1960. p. 22.

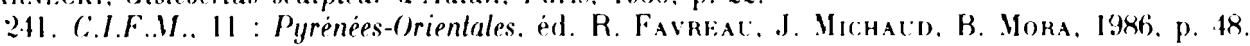

212. Ornamenla ecclesiae ... 2, p. 355): - Rainer B(DnF. Deulsche romanische Skulptur 1050-1250. Hunich. 1979. p. 61-6), ill. 10.4. 105 . 
outre, rappeler durablement sa mémoire et inviter en même temps à prier pour lui. L'épitaphe est très ordinaire pour les grands de ce monde, mais très fréquente aussi pour des catégories sociales beaucoup plus modestes. La mention de leur nom que les donateurs et les artistes font graver ou gravent sur leur ceuvre part du même souci de ne pas tomber dans l'oubli et de durer, par-delà leur mort, aussi longtemps que l'œuvre qu'ils ont réalisée ou aidé à réaliser. Épitaphes et mentions d'auteurs s'adressent précisément à tous ceux qui liront l'inscription, et feront ainsi "mémoire", "pour les siècles".

La chronique, les annales rappellent les grands événements, mais elles n'ont pas, surtout à l'époque du seul manuscrit, de possibilité ni de prétention à une très large information. Les inscriptions commémoratives, elles, se prêtent à une publicité générale et durable. De même l'intention d'assurer la publicité de certains actes publics ou privés, de certaines dispositions, a conduit aussi à reproduire sur pierre, sur marbre, les documents en leur intégralité ou l'essentiel de leur contenu. Ces inscriptions n'ont pas, précisément, valeur juridique, puisque leur seule fonction, complémentaire, est la publicité de l'acte.

Du point de vue religieux il convenait de rappeler des fêtes à célébrer, des obligations établies par des fondations d'anniversaires ou de services à remplir, des saints à fêter, ou de faire connaitre aux fidèles des octrois d'indulgence, d'où une série particulière d'inscriptions, à fonction proprement liturgique.

Enfin les grands programmes iconographiques devaient être commentés, surtout lorsqu'ils étaient inspirés par une riche pensée théologique. La nécessaire concision exigée par l'épigraphie a conduit à des formulations très denses et souvent admirables. Ces images qui décoraient les églises et leurs trésors étaient destinées à l'édification des fidèles, qu'il convenait aussi d'accueillir et d'instruire, d'où de fréquentes exhortations morales qui viennent en complément de l'explication théologique.

L épigraphie a deux caractères qui sont de tous les temps : la publicité, la durée. Les inscriptions remplissent des fonctions propres, à partir de l'état d'une société. Leur message, dès lors, nous renseigne sur une société à un moment donné, les hommes et les femmes, leur vie, leur culture, leur foi, leurs mentalités, des plus grands de ce monde et des plus belles ouvres aux plus simples et aux plus modestes édifices. Il s'agit d'un apport original, qui mérite d'être pris en compte systématiquement par tout médiéviste, qu'il soit historien, historien de l'art ou linguiste.

*Robert Favreau

C.É.S.C.M.-C.I.F.M.

24, rue de la Chaîne

F-86022 POITIERS 